\title{
A Novel methodology for planning of charging infrastructure in the scenario of high EV penetration
}

Mandhir Kumar Verma ( $\square$ mandhirverma@gmail.com )

Indian Institute of Technology Dhanbad https://orcid.org/0000-0002-1573-108X

\section{Vivekananda Mukherjee}

Indian Institute of Technology Dhanbad

\section{Vinod Kumar Yadav}

Delhi Technological University

\section{Santosh Ghosh}

Kirloskar Brothers Pune

\section{Research Article}

Keywords: Distribution network expansion planning (DNEP), electric busses (EBs), electric vehicles (EVs), Host charging station (HCS), response surface methodology (RSM)

Posted Date: February 14th, 2022

DOl: https://doi.org/10.21203/rs.3.rs-874556/v1

License: (c) (i) This work is licensed under a Creative Commons Attribution 4.0 International License. Read Full License 


\title{
A Novel methodology for planning of charging infrastructure in the scenario of high $\mathrm{EV}$ penetration
}

\author{
Mandhir Kumar Verma ${ }^{1, *}$, Vivekananda Mukherjee ${ }^{1}$, Vinod Kumar Yadav² and Santosh Ghosh ${ }^{3}$ \\ ${ }^{1}$ Department of Electrical Engineering, Indian Institute of Technology, Dhanbad, Jharkhand, India \\ ${ }^{2}$ Department of Electrical Engineering, Delhi Technological University, Delhi, India \\ ${ }^{3}$ Corporate R\&D Department, Kirloskar Brothers Limited, Pune, India
}

\begin{abstract}
This article presents a novel methodology for distribution network expansion planning (DNEP) considering the inclusion of electric vehicles (EV), especially, electric bus (EB) charging loads. The proposed methodology addresses network congestion through an optimum time of charging, cost optimization, new charging infrastructure, and minimization of losses under a set of technical and physical constraints, which represents practical uncertainties. Along with load flow analysis, selection of the number of ports and technology at the host charging station is obtained through the application of response surface methodology. The proposed methodology provides a coordinated planning for the development of EB charging station infrastructure that takes into account the effects of both the power dispersion framework and transportation framework. The effectiveness of the proposed methodology is investigated by applying it on 69-node IEEE modified distribution test system considering three charging technologies viz. fast charging, ultra-fast charging, and battery swapping. The results of the proposed model are compared with the direct statistical method and it revealed that the right selection of technology for EB charging and the right planning of the charging infrastructure can effectively optimize the cost of EV charging infrastructure and thereby catalyze the decarbonization of the transportation sector.
\end{abstract}

Keywords- Distribution network expansion planning (DNEP); electric busses (EBs); electric vehicles (EVs); Host charging station (HCS); response surface methodology (RSM)

\section{*Corresponding author.}

Tel.: $\quad+918448615745$

E-mail: mandhirverma@gmail.com (Mandhir Kumar Verma)

ORCID id: $\quad$ 0000-0002-1573-108X

\section{Introduction}

Electric vehicles (EVs), along with their charging infrastructures, are being deployed at a fast pace by city administrations across the globe to curb greenhouse gas emissions and reverse climate change. However, without proper planning, the introduction of a large number of charging stations will put an additional burden on the grid and thereby impact grid reliability. The optimal location of charging stations to ensure uninterrupted service of public transport and impact on the distribution system thereof are matters of great concern to the energy planners and the policymakers today. Charging station (CS) zones will require meticulous and innovative distribution network expansion planning (DNEP) to meet the additional demand due to the increased number of EVs, especially electric busses (EBs) (Xiang et al. 2019). EBs consume considerably higher energy than personal cars, and unplanned penetration of EBs will increase the losses, voltage drop, and overload the distribution network, which will eventually impact the system reliability and power supply quality (Gomez and Morcos 2002). Past studies show that, without adequate focus on DNEP, even a low penetration rate of EBs may lead to distribution transformer overloading (Li and Bai 2011), overshooting of peak load demand (Shao et al. 2009), and higher power losses (Hadley and Tsvetkova 2009). While planning for the charging infrastructure for the EB fleet, three vital strategic elements are essential to consider: where, when, and how to charge the EBs. Literature reveals that the optimal location of charging stations would improve the EB productivity and deliver unwavering quality and intensity of supply (Zhao et al. 2011), which will eventually encourage consumers to opt for this new mode of transport (Karfopoulos and Hatziargyriou 2013, Dong et al. 2018). Hence it is important to adopt smart charging technologies and positioning and scheduling of charging stations based on real-time data. The distance between the charging stations needs to be strategically maintained so that the EV users are not stressed over the possibility of a loss of energy in transit as well, and make the charging stations' location progressively sensible and predictable in the real world.

Much comparisons of planning strategies have been made by the researchers in the past. Zhao et al. 2020 compared over 20 research works related to the charging station planning, and the review of the past research shows that none of them considered integration of various types of charging technology, particularly for electric buses. Zeb et al. 2020 have compared normal and fast charging technologies with ultra-fast charging technology (UFCT) utilizing PSO technique. It has been shown that UFCT, when used along with photovoltaic generation, is more beneficial in all technical aspects as compared to normal and fast charging technologies. Complexity of planning of distribution network and changing infrastructure increses with consideration of renewable energy integration, as energy yield of those are intermittent and unpredictable (Ghosh and Yadav 2021, Yadav et al. 2021). A review on 
UFCT has also been done by Wang et al. 2021, which presents the impact of UFCT on battery life and grid. Along with the optimal setup of the charging station, (Nicolaides et al. 2019) compared the heating effects of diesel vs. electric while using the opportunity charging approach. No doubt that the electrification of any public transport route will yield more profit in the long run than conventional diesel buses. Battapothula 2019 has handled the burden on the distribution grid due to fast charging station load by optimally placing distributed generators in the system. While doing charging station planning, the most important factors considered are location, required load (which in turn depends upon the number and types of chargers), and investment (Chen et al. 2020).

Presently, load modeling based investigation and control methodologies are mainly adopted by the researchers to address the issues discussed above, viz. traffic simulation software (Galus et al. 2012), demographic model (Bessa and Matos 2013), parking generation rate model (Zhang et al. 2014), fuzzy logic system (Jingwei et al. 2014), Monte-Carlo technique (Yang et al. 2015), trip chain hypothesis (Tang and Wang 2016), Markov chain hypothesis (Wei et al. 2016), and dynamic traffic flow model (Xiang et al. 2016). Zhang et al. (2019) studied the location of charging stations for EVs and built a charging station location model based on the improved whale optimization algorithm. Most of the works found on charging stations and EVs have been brought up with metaheuristic techniques. While considering several design parameters and output responses for measuring the relative performance of the units, continuous refinements have been performed by the researchers by creating and collaborating various effective ranking methodologies for DNEP under uncertainty (Ghosh et al. 2017, Verma et al. 2016, 2019).

However, traditionally, DNEP is evaluated and executed through static techniques. In the present work, an innovative, dynamic evaluation and optimization technique was employed for siting and sizing of host charging station (HCS), based on response surface methodology (RSM) introduced by Box and Wilson 1951. The proposed methodology reconnoiters the relationships between innumerable critical design parameters and multiple response variables. Though numerous response variables increase the complexity because what is optimal for one response may not be so for the others, this problem can be subdued by reducing the variability of a single response (Khuri and Mukhopadhyay 2010).

RSM is an optimization tool which was initially introduced to advance information factors for obtaining maximum yield reaction parameters of any vitality change frameworks. However, due to its versatility and efficiency, its application has been extended to a wide and diverse field of research. While considering design parameters as battery capacity, PV size, and wind turbine rotor swept area, Ekren and Ekren (2008) optimized the hybrid system cost with RSM. Hasanien and Muyeen (2013) obtained the design parameters for the cascaded controller of the power conversion system unit using the Taguchi method, which was then verified by RSM and the genetic algorithm collaboration approach under the grid fault conditions. RSM has also been applied in the field of EV for optimization of charging infrastructure design (Bayram et al. 2013) in the past. The authors of this work proposed an effective scheme for optimization of charging procedure, which also increased the profitability of the CS operators. RSM has been applied in the field of machine design as well. The shape of the rotor slots of the EV induction motor was optimized by Jeon et al. (2011), in which the authors reported that the dynamic characteristics of the machine obtained through the application of RSM are most suited to EV. RSM has been reported to be effective in voltage stability analysis in power distribution system planning problems (Haesen et al. 2009, Wang et al. 2019 and Ren et al. 2016) as well. Two categories of RSMs, viz. the $2^{\text {nd }}$ order polynomial and the Kriging method, were applied to evaluate reliability and efficiency in transformer cooling system design optimization (Zhang et al. 2018). To manage the vulnerability of sustainable dispersed generators and the burden under fault conditions of the power distribution system, an assistance rebuilding technique dependent on stochastic RSM is proposed in Wang et al. (2019).

In the present work, a methodology for quantifying the optimal dispatch and charging of EBs is proposed considering three technologies: viz. fast charging technology (FCT), ultra-fast charging technology (UFCT), and battery swapping technology (BST) through the application of RSM as an optimization tool. A comparative analysis of these technologies is carried out while keeping economy, time of utilization, and infrastructure in mind, along with other technical and non-technical objectives and constraints. The proposed methodology removed decision-makers' subjectivity in weight assignment to the set of near-optimal solutions and relied on the statistical method, which is well proven in other fields of research. The main contributions of this paper are the following.

(a) A novel methodology is proposed for DNEP for the inclusion of charging stations for EBs, considering both technical and commercial aspects of planning. The placement and the sizing of HCS, along with the number of charging ports (CPs) at each $\mathrm{HCS}$, are considered to be the objective functions of the proposed methodology.

(b) Comparative analysis of the multiple near-optimal solutions is carried out against a set of criteria, including power losses, voltage deviations, and setup expenses.

(c) RSM is employed in the present work for obtaining the most optimal solutions from a set of near-optimal solutions.

The rationale behind the choice of RSM in the present work as the optimization tool is as below.

1. RSM enables solving multi-objective optimization problem.

2. Most of the other techniques provide one of the best solutions from a set of feasible solutions, whereas RSM precisely provides of the optimal solution, which may or may not be the same present in the search space.

3. RSM provides accurate results under probabilistic analysis (Wang et al. 2019).

Therefore, to handle different design variables, the RSM model built with the help oforthogonal arrays, is advantageous for obtaining the optimal solution (Hasanien 2013), and hence RSM is employed in the present work as an optimization tool.

After this introductory section, the rest of the article is organized as follows. Section 2 presents problem formulation comprising of assumptions, objectives, and constraints. Section 3 describes the EB specifications and battery charging optional technologies considered in the present work. The methodology is discussed in Section 4. Results and discussions are presented in Section 5. Finally, Section 6 delineates the conclusions of the present work. 


\section{Indices}

$f$

$i$

$k$

$l, L$

$m$

$n$

$N$

$t$

Sets

$T \quad$ Set of time intervals

$\psi_{N W 2} \quad$ Set of new wirings

$\psi_{B 1}, \psi_{B 2}$

$\psi_{S S 1}, \psi_{S S 2}$

$\psi_{F 1}$

$\psi_{N 1}, \psi_{N 2}$

Variables and parameters:

$C_{S P}^{U P}$
$C_{R P}^{U A}$
$C_{S H}^{S u b}$
$C C_{H C S}^{k}$
$C R S_{Z}$
$C P_{F}^{U P}$
$C P_{B P}^{U P}$
$C P_{U F}^{U P}$

$C_{U S E I}, C_{U S E I, k W}$

$C_{C S C}, C_{C S C, k W}$

$d$

EC

$E_{\text {tot }, n}$

$E_{i}^{r a t}$

$I_{l, t}$

$I_{n, t}{ }^{*}$

$I_{f}^{\text {Low }}, I_{f}^{U p}$

$L_{H C S O}^{k}$

$L_{F C}^{k}, L_{U F C}^{k}, L_{B S}^{k}$

$L_{F C}^{c a p}, L_{U F C}^{c a p}, L_{B S}^{\text {cap }}$

$M C B_{i}$

N

$N_{L P 2}$

$N_{F C P}^{k}$

$N_{U F C P}^{k}$

$N_{B S P}^{k}$

$N_{S B}^{k}$

$N_{R A}^{k}$

$N_{C P 1}$

$N_{m t h}$

$N_{B r 1}, N_{B r 2}$

$N_{S S 1}, N_{S S 2}$

$P_{E B m}$

$P R, P R$ kW

$P_{E B_{m}}$

$P_{\text {max }}$

$r_{o}$

$R C_{i}^{\exp }$

$R C_{i, t}$

$R C B_{m}$

$R_{l}$

$S_{n, t}$

For spare battery

For feeder section

For network line

For network nodes

For time

Resistance of line $l$
For electric bus (EB)

For host charging station (HCS)

For charging ports (CP)

For number of technology ports

Set of primary network branches (existing and proposed)

Set of substations (existing and planned)

Set of the feeder of system

Set of number of bus substation nodes (existing and planned)

Spare battery unit price

Swapping robotic arm unit price

Cost of selected heads falling under government subsidy scheme

Capital costs for the $k^{\text {th }}$ HCS

Customer reliability of service at load point $\mathrm{z}$

Unit price of fast ports

Unit price of ultra-fast ports

Unit price of battery swapping ports

Upstream electrical infrastructure total cost and per $\mathrm{kW}$ cost

Charging system component total cost and per $\mathrm{kW}$ cost

Difference of number of CP considered for every charging technology at each step

Energy charges as per State electricity regulatory commission's notification

Total energy delivered to $n^{\text {th }}$ node over the period

Rated capacity of the $i^{\text {th }}$ EB battery

Current of line $l$ at time $t$

Current difference between two adjacent lines at time $t$

Lower and upper bound of current magnitudes at feeder section $f$

Operational load of HCS $k$

Load for all FCT, UFCT, and BST ports at HCS $k$

Load capacity of each FCT, UFCT, and BST ports at HCS $k$

Maximum capacity of the battery of the $i^{\text {th }} \mathrm{EB}$

Maximum number of technology ports of any one technology out of the three considered

that can be installed at HCS

Maximum number of new connected load points

Proposed number of fast charging ports at $k^{\text {th }} \mathrm{HCS}$

Proposed number of ultra-fast charging ports at $k^{\text {th }}$ HCS

Proposed number of battery swapping ports (slow charging) at $k^{\text {th }} \mathrm{HCS}$

Proposed number of spare batteries (for battery swapping) at $k^{\text {th }}$ HCS

Proposed number of swapping robotic arm at $k^{\text {th }} \mathrm{HCS}$

Number of active CP

Number of days in a month

Number of primary network branches (existing and proposed)

Number of substations (existing and planned)

Power delivered to EB connected at the $m^{\text {th }} \mathrm{CP}$

Total power required at $\mathrm{HCS}$, in $\mathrm{kW}$

Power demand of EB at $m^{\text {th }} \mathrm{CP}$

Maximum charging power

Discount rate offered by the state government

Expected residual charge (RC) of the $i^{\text {th }} \mathrm{EB}$

Real-time battery refresh charging of the $i^{\text {th }} \mathrm{EB}$ at time $t$

Residual charge in EB (in $\mathrm{kWh}$ ) connected at $m^{\text {th }} \mathrm{CP}$

Load at node $n$ at time $t$ 


\begin{tabular}{|c|c|}
\hline \multirow{2}{*}{\multicolumn{2}{|c|}{ Minimum and maximum allowable load at node $n$ at time $t$}} \\
\hline & \\
\hline$S_{b, f, s s}, S_{b, f, s s}^{\max }$ & Power (and max power) flow in branch $b$ of the network feeder $f$ at substation $s s$ \\
\hline$S_{i}$ & Initial state of EB with a full charge and at first stop of the route \\
\hline$S_{i+}, S_{k+}$ & State of EB during one-way trip of first/next round \\
\hline$S_{j}$ & State of EB at last stop of one-way trip of the first round \\
\hline$S_{j+}, S_{l+}$ & State of EB during the returning trip of first/next round \\
\hline$T_{F C P}^{c}$ & Charging times taken by FCT port for an SOC of $90 \%$ \\
\hline$T_{U F C P}^{c}$ & Charging times taken by UFCT port for an SOC of $80 \%$ \\
\hline$T_{B S P}^{c}$ & Charging times taken by BST port for an SOC of $100 \%$ \\
\hline$T_{F C}, T_{U F C}, T_{B S}$ & Time periods of the day for which each FCT, UFCT and BST port utilized \\
\hline $\begin{array}{l}T_{F C B L}, T_{U F C B L}, \\
T_{B S B L}\end{array}$ & $\begin{array}{l}\text { Useful time span of spare battery charged with: FCT port, UFCT port and BST port } \\
\text { respectively }\end{array}$ \\
\hline$T L L_{T X_{\text {init }}}$, & Initial and maximum thermal loading limits of distribution network transformer \\
\hline$T L L_{T X_{\max }}$ & \\
\hline$T L L_{L_{\text {init }}}$ & Initial and maximum thermal loading limits of distribution network line \\
\hline$T L L_{L_{\max }}$ & \\
\hline$T_{P}$ & Time horizon of planning \\
\hline$T_{O H}$ & Outage hours of load node \\
\hline$V_{n, t}$ & Voltage at node $n$ at time $t$ \\
\hline$V_{\text {init }, m}$ & Initial voltage at $m^{\text {th }} \mathrm{CP}$ with no $\mathrm{EB}$ connected \\
\hline$V_{\min , m}, V_{\max , m}$ & Minimum and maximum voltage at the $m^{\text {th }} \mathrm{CP}$ when an EB is connected. \\
\hline$W^{b k W}$ & Rated power of the battery in $\mathrm{kW}$ \\
\hline$W^{b k W t}$ & Rated capacity of the battery in $\mathrm{kWh}$ \\
\hline$x$ & Available area of substations for expansion. \\
\hline$x_{m}$ & Status of EB connection with $m^{\text {th }} \mathrm{CP}$ \\
\hline$X_{t}^{b}$ & Energy in the battery in time interval $t$ \\
\hline$X_{t}^{b-}$ & Power to the battery in time interval $t$ \\
\hline$\Delta$ & Power incremental limit by which the charging rate can vary in $\mathrm{kW}$ \\
\hline$\mu_{m m}, \mu_{m p}$ & $\begin{array}{l}\text { Sensitivity of voltage at } m^{\text {th }} \mathrm{CP} \text { due to EB power demanded at the } m^{\text {th }} \mathrm{CP} \text { and the } p^{\text {th }} \\
\mathrm{CP} \text {, respectively in V/kW. }\end{array}$ \\
\hline$\delta_{m}$ & $\begin{array}{l}\text { Sensitivities of the distribution network transformer to power demand of EB at } m^{\text {th }} \mathrm{CP} \\
\text { in } \mathrm{kVA} / \mathrm{kW}\end{array}$ \\
\hline$\beta_{m}$ & $\begin{array}{l}\text { Sensitivities of the distribution network line to power demand of } \mathrm{EB} \text { at } m^{\text {th }} \mathrm{CP} \text { in } \\
\mathrm{kVA} / \mathrm{kW}\end{array}$ \\
\hline$\eta_{c}$ & Charging efficiency \\
\hline
\end{tabular}

\section{Problem formulation}

The main objective of the present work is to derive the placement (location) and sizing (number and capacity of charging ports) of HCS, considering several economic, technical, and non-technical objective functions, under physical and capacity constraints.. Also several parameters are considered based on the socio-economic characteristics of the region under study (city of Delhi, India in this case) to increase the feasibility of the solution. The complete methodology adopted in the present work is delineated in in Figure 1. In order to make the problem formulation closer to the real-world scenario, in the present work, the parameters and constraints of the city of Delhi, India, are considered. For the present case (i.e., the city of Delhi), the Government of Delhi (GoD) has planned the induction of $1000 \mathrm{EBs}$ and identified six locations for constructing the parent charging stations (PCSs), which will facilitate parking and charging the EBs overnight by normal charging mode. For ensuring equal distribution charging load, about 166 EBs are allotted to each PCS. Further, each PCS will cater to several sub-PCSs (e.g., Rohini PCS is planned to have four sub-PCSs), and, hence, each sub-PCS will be catering to about 40-45 EBs. The schedule and route of plying of EBs are considered to be the same as that of the presently running busses on compressed natural gas (CNG). Practically length of all the routes are greater than $50 \mathrm{~km}$, and each busses are required to ply to and fro (from the PCS to the end of the route) at least twice per day. The stoppage time (or idle time) is considered as ten seconds for embarkation and /disembarkation of commuters at bus stops, stoppages at traffic signals, and stoppages on-road due to congestion. The maximum speed of the chosen EBs is considered to be $75 \mathrm{~km} / \mathrm{h}$, and the maximum distance which can be covered by those is considered to be $151 \mathrm{~km}$ per charge (full) ${ }^{1}$. Hence, the EB running at any specific route will require midway charging to ensure uninterrupted service to the commuters. Normal charging will require more than two hours for re-charge, which will not be a feasible option of charging while the EBs are in transit.

In the proposed solution, a different mode of charging is considered for different times of the day. The EBs shall be charged at their PCS in normal mode and leave the PCS in a fully charged condition. For refresh charging while plying between the PCS and the final stop, the EBs are considered to halt at HCSs and get charged by either FCT, UFCT, or BST. For all EBs as well as for BST spare battery units, the Li-ion battery is considered for the present case. 


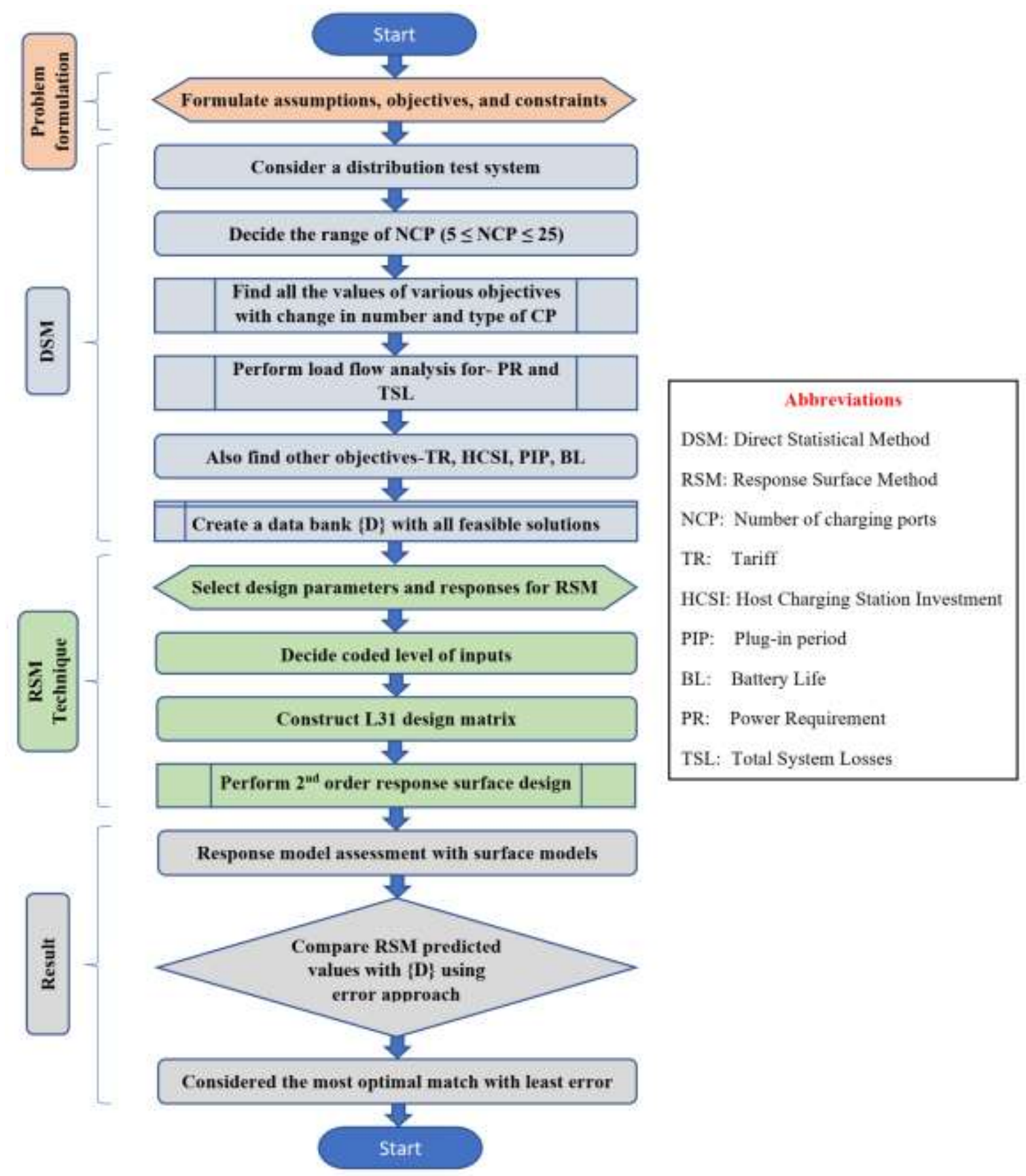

Fig. 1 Flow chart of the entire methodology.

\subsection{Assumptions}

Assumptions on some of the parameters are made regarding the optimization model, information on which are not available in the public domain. These assumptions may vary as per the discretion of the planner, for studies on different cities based on the priorities and objectives to be achieved, equality, and inequality constraints for keeping the pool of solutions under bounded conditions. While considering the overall cost, capital cost for extra batteries and setup cost for HCS is assumed in the present work, as detailed information on the same could not be found. The cost of land required for setting up the charging stations is not considered while estimating the overall cost. It is assumed that excess land available with city public transport authorities shall be used for setting up the charging stations. The EB battery charging process is considered to be a continuous,i.e., without any voltage fluctuation and power cut, until the charging state of up to $85 \%$ capacity is reached. It is also considered that every EB will get seven hours in the night for a full normal charge, and it will leave PCS with full SOC.

Each fast and ultra-fast charging point is considered to be equipped with smart metering and load control capability. EBs cannot deliver power back to the grid, so the bi-directional flow of electricity is not considered. The EBs battery capacity utilization depends directly upon the actual distance traveled. A safety margin charge reserve is kept for every EB to deal with all odds against running out the power capacity.

DC chargers are considered instead of AC ones, as in case of AC chargers, high power rectifiers will be required to be installed in EB, which will consume additional space and will increase the cost of EB. Battery swapping technology consists of a charging system (done with normal charging technology (NCT)) and a robotic swapping mechanism. The charging of spare batteries can be done on-station as well as off-station. Off-station charging may be done to take advantage of the lower tariff in case of space scarcity.

The charging process of spare batteries is considered to be a continuous and cyclical process ( 24 hours). The spare batteries will get charged by NCT in 6-7 hours, whereas the swapping process will take place in around 5 minutes duration. While the EBs will 
get charged overnight by NCT at PCS, charging of spare battery packs will happen at HCS. The side-swapping method is considered in the present work for BST operation. Considering one swapping per hour, every HCS must have a minimum of 8 spare charged batteries, and further, if the number of ports is greater than 5, then the number of spare batteries must be equal to the thrice number of ports available at that particular HCS.

\subsection{Objectives}

This section describes various technical and non-technical objectives taken into consideration for optimizing the charging of EBs with optimal DNEP.

(a) HCS investment (HCSI): The first objective function considered for the optimization model of DNEP is to minimize the total investment for each type of HCS, as noted in (1) $\min H C S I=\left(N_{F C P}^{k} C P_{F}^{U P}+N_{U F C P}^{k} C P_{U F}^{U P}+N_{B S P}^{k} C P_{B S}^{U P}+C C_{H C S}^{k}+N_{S B}^{k} C_{S B}^{U P}+N_{R A}^{k} C_{R A}^{U P}-r_{o} C_{S H}^{s u b}\right)$

Where the terms used can be explained with the following equations $((2)-(5))$ :

$$
\begin{gathered}
C C_{H C S}^{k}=C_{U S E I}+C_{C S C} \\
C_{U S E I}=C_{U S E I, k W} \times P R_{k W} \\
C_{C S C}=C_{C S C, k W} \times P R_{k W} \\
C_{S H, \text { sub }}=N_{F C P}^{k} C P_{F}^{U P}+N_{U F C P}^{k} C P_{U F}^{U P}+N_{B S P}^{k} C P_{B S}^{U P}+N_{R A}^{k} C_{R A}^{U P}+C_{C S C}
\end{gathered}
$$

The first, second, and third terms in (1) represent charging ports cost of the fast, ultra-fast, and battery swapping technologies, respectively. The fourth term represents capital cost, the fifth and sixth terms represent spare battery cost and robotic arm cost, respectively, and the last term represents the subsidy provided by the Government of India (GoI). All N represent various ports quantities.

(b) Number of Charging Points (NCP): As per the GoI guidelines for setting up EV charging infrastructure (under Faster Adoption and Manufacturing of Electric Vehicles (FAME) India Scheme, phase-II), a minimum of five chargers of any one or combination of slow and FCT is mandatory (TGOI 2019, DHI FAME-II 2019). In the present work, all the NCPs are considered to be a combination of BST, FCT, and UFCT based ports. Because of space constraints in the city, the maximum NCP is considered as 25 . The number of configurations is a function of $N$, and may be obtained using (6)

$$
C P=\frac{N+1}{2}[2 a+N d]
$$

where, $a$ is the initial number of CP considered for any charging technology (i.e., one for all the cases and a minimum of 3 ).

(c) Plug-in period (PIP): The plug-in period is considered as the average time taken by each EBs in the queue to get charged in a scenario when all the charging points in an HCS are occupied (in use). Plug-in-period is governed by (7).

$$
P I P=\frac{N_{F C P}^{k} \times T_{F C P}^{c}+N_{U F C P}^{k} \times T_{U F C P}^{c}+N_{B S P}^{k} \times T_{B S P}^{c}}{N_{F C P}^{k}+N_{U F C P}^{k}+N_{B S P}^{k}}
$$

(d) Battery Life $(B L)$ : Battery life is considered as 'long' for normal charging. While quantifying battery life, the ambient temperature conditions and driving style of drivers are not considered. Literature reveals that as compared to uncontrolled charging, controlled normal charging yields $15.8 \%$ more battery life (Jafari et al. 2018). Accordingly, the governing equation for average battery life (BL) calculation may be represented by (8).

$$
B L=\frac{N_{F C P}^{k} \times T_{F C B L}+N_{U F C P}^{k} \times T_{U F C B L}+N_{B S P}^{k} \times T_{B S B L}}{N_{F C P}^{k}+N_{U F C P}^{k}+N_{B S P}^{k}}
$$

As the sensitivity of the voltage level has a negative correlation with the proximity of additional load to the transformer (Richardson et al. 2012), EBs connected closer to the transformer will get charged at a higher rate, especially in a radial distribution network. To balance the load on the distribution network for maximizing its capacity utilization, the charging rate of each EB must be optimized to maximize the energy delivery to all connected EBs at all times. So, to rank batteries with a low residual charge in battery (RCB), while assuming that the RCB of each EB is known at the commencement of individual optimization time step (a short time interval of $15 \mathrm{~min}$ is assumed), the function for maximization of energy delivery to all EBs is expressed as in (9).

$$
\mathcal{F}=\sum_{i=1}^{N_{C P 1}} 1-\left(\frac{R C B_{m}}{M C B_{m}}\right) P_{E B m} x_{m}
$$

This energy delivery optimization will ultimately impact the battery life in the long run; hence, (9) is also considered as the objective for achieving longer battery life. Here, $x_{m}$ which denotes status of EB connection with CP will be ' 0 ' when not connected and is ' 1 ' when connected. Hence this energy delivery to all EBs is considered as integral part of BL.

(e) Power requirement (PR): Total PR (including operational power required for each HCS) is governed by (10).

$$
P R=L_{F C}^{k}+L_{B S}^{k}+L_{U F C}^{k}+L_{H C S O}^{k}
$$

(f) Total system losses (TSL): The loss minimization (Verma et al. 2019) is expressed by (11).

$$
\left.P_{\text {Loss } \min }=\sum_{\substack{t-1 \\ t \in T}}^{T} \sum_{l=1}^{L} R_{l} I_{l, t}^{2}\right\}
$$

(g) Tariff $(T R)$ : The tariff fluctuate as per the power demand. The demand depands upon type and number of carging ports. Tariff calculations per month is governed by (12)

where

$$
T R=\left[\left(L_{F C}^{k} \times T_{F C}\right)+\left(L_{U F C}^{k} \times T_{U F C}\right)+\left(L_{B S}^{k} \times T_{B S}\right)+\left(L_{H C S O}^{k} \times 24\right)\right] N_{m t h} \times E C
$$

$$
\begin{gathered}
L_{F C}^{k}=N_{F C P}^{k} \times L_{F C}^{c a p} \\
L_{U F C}^{k}=N_{U F C P}^{k} \times L_{U F C}^{c a p}
\end{gathered}
$$




$$
L_{B S}^{k}=N_{B S P}^{k} \times L_{B S}^{c a p}
$$

\subsection{Constraints}

At each time interval, the objective functions described in subsection 2.2, can be optimized (minimized or maximized) subject to certain constraints. To obtain optimal values of system losses, power flow, thermal loading and optimal EB charging, the following constraints are considered in the present work.

(a) The energy storing system constraints are described as follows. The boundation on the power supply to the battery in any time interval (which cannot exceed the rated charging power) is expressed by (16).

$$
\begin{array}{crl}
X_{t}^{b-} \leq W^{b k W} & \forall t & \in T \\
X_{t}^{b} \leq W^{b k W t} & \forall t & \in T \\
\left(P_{E B m}^{t-1}-\Delta\right) \leq P_{E B m}^{t} \leq\left(P_{E B m}^{t-1}+\Delta\right)
\end{array}
$$

Moreover, the boundation on the energy stored in the battery in any time interval (which cannot exceed the rated capacity) is expressed by (17). A charging rate variation constraint is also imposed by (18) keeping in mind the present battery technology (Hadley and Tsvetkova 2009).

(b) The constraints related to minimum loss are expressed by (19)-(23):

where,

$$
S_{n, t}=V_{n, t}\left(I_{n, t}\right)^{*}
$$

$$
I_{n, t}=I_{l, t}-I_{l+1, t}
$$

s.t.

$$
\begin{aligned}
& S_{n, t} \geq S_{\min , n, t} \\
& S_{n, t} \leq S_{\max , n, t} \\
& \sum_{t} S_{n, t}=E_{t o t, n}
\end{aligned}
$$

(c) The constraint for maintaining voltage level and deviation $\left(V_{\text {dev }}\right)$ within allocated limits can be summarized as in (24) and (25).

$$
\begin{gathered}
V_{\text {min }, m} \leq\left[\begin{array}{c}
\left.V_{\text {init }, m}+\mu_{m m} P_{E B, m}+\sum_{p=1}^{N} \mu_{m p} P_{E B, j}\right] \leq V_{\text {max }, m} \\
m \forall N, m \neq p
\end{array}\right\} \\
V_{\text {dev }}=\left[\frac{V_{\text {min }, m}-V_{\text {max }, i}}{2 . V_{\text {init }, m}}\right] \cdot 100 \%
\end{gathered}
$$

(d) Branch current flow constraints are expressed as (26).

$$
I_{f}^{\text {Low }} \leq I_{f} \leq I_{f}^{U p}
$$

(e) Operational radiality of the distribution network is imposed by (27), which will ensured that the basic rules are obeyed in the planning model (Zhang et al. 2014),

$$
\sum_{i \in \psi_{N W 2}} N_{B r 2}=N_{L P 2}-\sum_{s 2 \in \psi_{S S 2}} N_{S S 2}
$$

(f) The thermal loading constraints for distribution network transformers and lines are summarized as in (28) and (29).

$$
\begin{aligned}
& T L L_{T X_{\text {init }}}+\sum_{k=1}^{N} \delta_{m} P_{E B_{m}} \leq T L L_{T X_{\text {max }}} \quad k \forall N \\
& T L L_{L_{\text {init }}}+\sum_{k=1}^{N} \beta_{m} P_{E B_{m}} \leq T L L_{L_{\text {max }}} \quad k \forall N
\end{aligned}
$$

(g) Power flow capacity constraints can be quantified by (30).

$$
\left.\begin{array}{c}
\left|S_{b, f, s s}\right| \leq S_{b, f, s s}^{\max } \\
b \in \psi_{B 1}, \\
f \in \psi_{F 1}, \\
s s \in \psi_{N 1}, \psi_{N 2}
\end{array}\right\}
$$

(h) Reliability constraints are expressed by (31) and (32). Here, (31) ensures that service reliability remains in upper and lower allowable values and power shortage rate reliability is expressed by (32).

$$
\begin{aligned}
& C R S_{Z}^{\text {min }} \leq C R S_{Z} \leq C R S_{Z}^{\max } \\
& C R S_{Z}=1-\frac{T_{O H}}{T_{P}}
\end{aligned}
$$

(i) During DNEP for charging EBs, constraints on charging station are given by (33), which also ensures that at least five new charging points (term $N_{C P 2}$ ) can be added to the existing station.

$$
\sum_{t=1}^{T} \sum_{s s=1}^{N_{S S 1}} x_{m, t, s s} \leq N_{C P 2} \quad \forall j \in \psi_{S S 1}, \psi_{S S 2}
$$

(j) The proposed HCSs will exclusively serve the EBs, which will have to be commercially viable and, hence, the least plug-inperiod (PIP) is to be ensured to avoid loss of revenue due to waiting time. Hence, a PIP constraint is imposed on every HCS to achieve the financial sustainability of the EB operation, which can be mathematically expressed by (34).

$$
T_{i, t}^{\min } \leq P I P \leq 50
$$


where the minimum duration needed to plug in EB to achieve desirable charging requirements $\left(T_{i, t}^{\min }\right)$, which can be mathematically defined as:

$$
T_{i, t}^{\min }=\left\{\begin{array}{lc}
\frac{E_{i}^{r a t}\left(R C_{i}^{e x p}-R C_{i, t}\right)}{\eta_{c} \cdot P_{\max }} & R C_{i, t}<R C_{i}^{\text {exp }} \\
0 & R C_{i, t} \geq R C_{i}^{\text {exp }}
\end{array}\right.
$$

\section{EBs charging: when, where, and how?}

It is considered that the location of the HCS on each route should be such that the EBs reaching the HCS shall have SOC of 10 to $20 \%$, and 80 to $85 \%$ while leaving. This is so because the EBs must reach the HCS before complete drain-out and will leave the HCS before $100 \%$ SOC as the last $20 \%$ of charging is slow and require more time as compared to the time taken to reach $20 \%$ to $80 \%$ SOC.

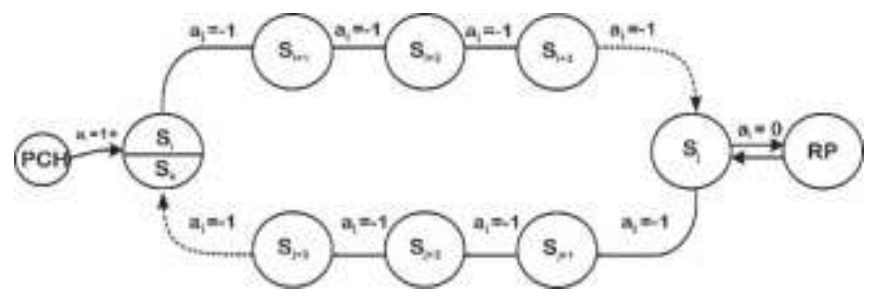

(a)

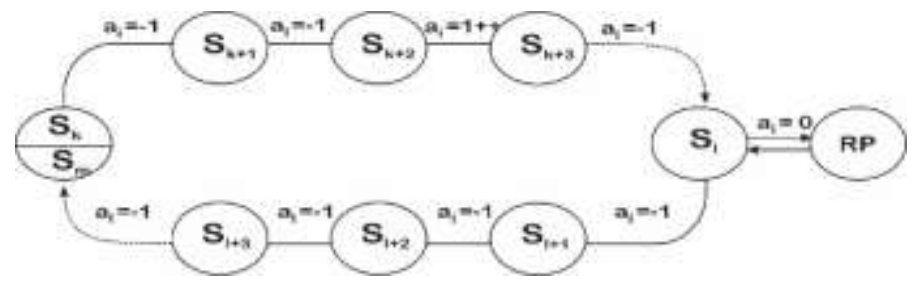

(b)

Fig. 2 Charging and discharging state alteration process of EB (a) First round trip of the day (b) Next consecutive rounds

The charging and discharging state alteration process of EB is shown in Figure 2, in which the terms shown outside the circle have the following interpretations:
$a_{i}=-1$
$a_{i}=0$
represents the driving state of $i^{\text {th }} \mathrm{EB}$,
$a_{i}=1+$ represents ideal state of $i^{\text {th }} \mathrm{EB}$,
$a_{i}=1++$ normal charging or fast charging of $i^{\text {th }} \mathrm{EB}$ at PCS ultra-fast charging or battery swapping of $i^{\text {th }} \mathrm{EB}$ at HCS

\section{Methodology}

In the present work a 69-node IEEE modified distribution test system (Savier and Das 2007) is considered to evaluate the effect of EBs' charging on the power quality and reliability. The reconfigured system is modified by utilizing tie switches based on the fuzzy multi-objective approach.

The single line diagram of the 69-node IEEE modified distribution test system, as shown in Figure 3, has 68 branches with normally closed switches without any tie lines. The current carrying capacity of branches 1-9 is 400 A, of branches 25 , 40, 49-51, 5359, 61-65 is $300 \mathrm{~A}$, and for the rest of the branches are $200 \mathrm{~A}$. The system base voltage and MVA are assumed at $12.66 \mathrm{kV}$ and 100 MVA, respectively. The rest of the section is divided into three parts describing design parameters, output responses, and the methodology used.

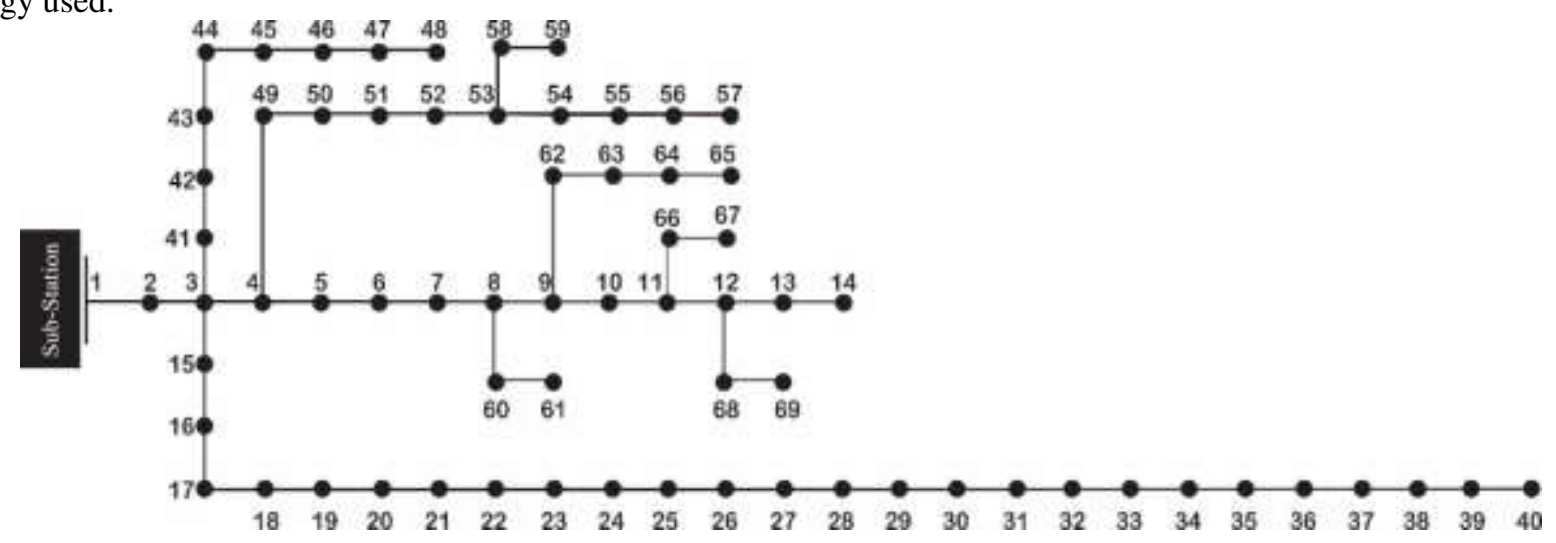

Fig. 3 Single-line diagram of 69-node IEEE modified distribution test system 


\subsection{Direct Statistical Method (DSM)}

For producing the pool of feasible solutions, direct statistical method is utilized. The computational region for optimizing the sitting and sizing of HCS is based upon seven objectives. To strengthen the mathematical modelling of various objectives, the considerations are explained below.

(a) Host charging station investment (HCSI): Creating apposite FCT infrastructure is the key for speedy electrification of the bus fleet. However, the following two concerns are typically cited as crucial issues - minimization of the cost of the FCT infrastructure and up-gradation of power system for coordinating the charging load. HCSI is one of the design parameters for the present work. Main terms are considered in (1), and their further classifications are given in (2) - (5)). The capital cost for setting up HCS in India is calculated based on the data given in Table 1.

Table 1 Bifurcation of the HCS establishment capital cost

\begin{tabular}{lll}
\hline Investment Head & $\begin{array}{c}\text { Unit Price } \\
(₹ \mathrm{M})\end{array}$ & Ref. \\
\hline BST port $(20 \mathrm{~kW})$ & 0.24 & TGOI (2019), DHI FAME-II (2019) \\
FCT port $(50 \mathrm{~kW})$ & 0.725 & TGOI (2019), DHI FAME-II (2019) \\
UFCT port $(450 \mathrm{~kW})$ & 1.5 & TGOI (2019), DHI FAME-II (2019) \\
DRDO Li-ion spare battery & 0.5 & TET (2015) \\
Subsidy provided by GOI ${ }^{2}$ & $70 \%$ & TGOI (2019), DHI FAME-II (2019) \\
Capital investment & & \\
\hline Upstream electrical infra (per $\mathrm{kW})$ & 0.005476 & Pillai et. al. (2018) \\
Charging system component cost (per kW) & 0.017982 & Pillai et. al. (2018) \\
\hline
\end{tabular}

Three swapping robotic arms are considered for each HCS configuration. An exchange rate of ₹ 74 per USD is considered while calculating the capital cost.

(b) The number of charging points (NCP): Table 2 shows the number of configurations of charging ports at HCS formed due to various charging technologies (as per (6)), which sum up to 3241 configurations. For example, if the total charging ports to be installed at an HCS are 6 (BST, FCT, and UFCT based ports), the second row (No. of configurations) presents total permutation and combinations of 6 ports.

Table 2 Number of configurations of charging ports

\begin{tabular}{llllllllllll}
\hline $\mathrm{N} \quad \begin{array}{c}\text { (Number of } \\
\text { charging ports) }\end{array}$ & 5 & 6 & 7 & 8 & 9 & 10 & 11 & 12 & 13 & 14 & 15 \\
No. of configurations & 21 & 28 & 36 & 45 & 55 & 66 & 78 & 91 & 105 & 120 & 136 \\
\hline $\mathrm{N} \quad \begin{array}{c}\text { (Number of } \\
\text { charging ports) }\end{array}$ & 16 & 17 & 18 & 19 & 20 & 21 & 22 & 23 & 24 & 25 \\
No. of configurations & 153 & 171 & 190 & 210 & 231 & 253 & 276 & 300 & 325 & 351 \\
\hline
\end{tabular}

(c) Plug-in-period (PIP): PIP is calculated by considering that, for a particular CP configuration, all types of CPs are occupied, and the next EB in the queue will require an average time of all types of CP duration (expressed in (7)). The charging time is considered as 5, 15, and 120 minutes for BST, UFCT, and FCT, respectively (An et al. 2019). In the case of battery swapping, the charging time will be the same as normal charging. However, the time which is considered in the present work is that time which the EB will consume in the swapping process.

(d) Battery life $(B L)$ : Battery life is considered 'long' for normal charging. Accordingly, the governing equation for average BL, the expression may be represented by (8), and for economic consideration, (8) must be maximized.

(e) Power requirement (PR): Total power required (including operational power required) for each HCS is governed by (10). The whole planning revolves around the power required for charging EBs in a minimum time frame. Hence, this response is maximized during optimization compared to other DNEP problems, where the planner targets to minimize this response.

(f) Total System losses (TSL): The fundamental objective and constraint equations for total system losses are described in (11) and (19)-(23), respectively, and the calculations are carried out by performing load flow analysis on 69-node IEEE modified distribution test system (see Figure 3) in MATLAB R2017a environment. It is obvious that the minimization of TSL is targeted in the present work.

(g) Tariff (TR): Delhi electricity regulatory commission has introduced a separate energy tariff (substantially lower than industrial tariff) for EV charging stations, which are ₹ 4/kWh for charging from HT network and ₹ 4.5/kWh for charging from LT network (DERC 2019). There are no fixed monthly charges applicable as well. The same is considered in the present work. Tariff calculations per month is governed by (12). UFCT port utilization-based consumption is considered 4 hours for up to 10 ports, 3 hours for 10-20 ports, and 2 hours for more than 20 ports. A $20 \mathrm{~kW}$ of continuous (for all-day) load is considered for the rest of the power consumed in HCS. As per the guidelines of the Ministry of Power, GOI (GoI-MoP 2018), for normal charging (as well as for battery swapping), $15 \mathrm{~kW}$ (model- Bharat DC-001) charger and, for fast charging, $50 \mathrm{~kW}$ (CHAdeMO) charger is considered for each charging port. The off-board DC chargers for ultra-fast charging is considered as super-chargers having $450 \mathrm{~kW}$ capacity (Muratori et al. 2019). From a total of 3241 configurations, the maximum and minimum values of the seven objectives are summarized in Table 3. 
Table 3 Summary of calculated results with DSM

\begin{tabular}{|c|c|c|c|c|c|c|c|c|c|c|c|}
\hline & Indexing & & Charging & ports & & HCS & TR & BL & PR & TSL & PIP \\
\hline & & $\begin{array}{l}\text { No of } \\
\text { FCT } \\
\text { Ports }\end{array}$ & $\begin{array}{l}\text { No of } \\
\text { UFCT } \\
\text { Ports }\end{array}$ & $\begin{array}{l}\text { No of } \\
\text { BST } \\
\text { Ports }\end{array}$ & NCP & & & & & & \\
\hline $\begin{array}{l}\text { Lowest } \\
\text { value }\end{array}$ & 1 & 05 & 05 & 05 & 05 & 04.43 & 0.432 & 4.210 & 00.12 & 0.1903 & 05.00 \\
\hline $\begin{array}{l}\text { Highest } \\
\text { Value }\end{array}$ & 3241 & 25 & 25 & 25 & 25 & 134.04 & 4.482 & 5.000 & 11.27 & 0.6991 & 50.00 \\
\hline
\end{tabular}

\subsection{The optimization model: RSM}

Response surface methodology (RSM) is an optimization technique used to acquire the exact models of the design parameters in terms of response factors in the wake of recognizing their relative commitment, utilizing the Taguchi technique. The strategy for steepest ascent/descent can be successfully used to recognize the ideal estimations of the responses.

RSM addresses a diverse set of queries, for example:

(a) How is a specific output influenced by a given arrangement of information factors over some predetermined area of interest?

(b) To what extent, the information sources are to be controlled to give an item, fulfilling required details.

(c) What estimations of design parameters will yield the greatest for an appropriate response, and what is the idea of response surface near the most extreme?

If the output is very much displayed by a direct capacity of the autonomous factors, at that point, the approximating capacity is the first-order model. If there is a curvature in the framework, at that point, a polynomial of a higher degree must be utilized, for example, the second-order model. This model would almost certainly be valuable as a guess to the genuine response surface in generally smaller sections. The second-order model is generally utilized in RSM for the following reasons:

(a) The second-order model is truly adaptable. It can take on a wide assortment of practical structures, so it will regularly function admirably as a guess to the genuine response surface.

(b) Utilizing the technique for least squares, it is easy to evaluate the parameters in the second-order model.

There is significant handy experience as well as literature available, showing that second-order models function admirably in taking care of genuine response surface issues (Haesen et al. 2009, Ren et al. 2016, Wang et al. 2019). The relationship between a response $(y)$ and of the set of associated design parameters $\left(x_{1}, x_{2}, \ldots, x_{k}\right)$ can be mathematically expressed as in (36).

$$
y=\beta f^{\prime}(x)+\varepsilon
$$

And, for a second-order model, it is expressed as in (37)-(38).

$$
\begin{aligned}
& y=\beta_{o}+\sum_{i=1}^{k} \beta_{i} x_{i}+\sum \sum_{i<j} \beta_{i j} x_{i} x_{j}+\sum_{i=0}^{k} \beta_{i i} x_{i}^{2}+\varepsilon \\
& p=1+2 k+\frac{1}{2} k(k-1) \\
& \frac{1}{n} \sum_{u=1}^{n} x_{u i}=0 \\
& \frac{1}{n} \sum_{u=1}^{n} x_{u i}^{2}=1 \\
& i=1,2, \ldots, k \\
& u=1,2, \ldots, n
\end{aligned}
$$

where $x=x_{1}, x_{2}, \ldots, x_{k}$, and $f^{\prime}(x)$ is a vector function of elements $p$ which consists of powers and cross-products of powers of $x$ up to a certain degree represented by the positive integer $d, \beta$ is a vector of $p$ unknown constant coefficients (parameters), $\varepsilon$ is random error in the experimental result, $n$ is number of experiments and $x_{u i}$ is the $u^{\text {th }}$ setting of the $i^{\text {th }}$ control variable. Here, $u=1,2, \ldots, n$. Central composite design (CCD): One of the most popular second-order designs, CCD consists of three constituent parts (Khuri and Mukhopadhyay 2010). The first one is a factorial portion, which consists of $2^{k}$ factorial design whose factors' levels are coded as $-1,1$. The second one is an axial portion consisting of $2 k$ points arranged so that two points are picked on the hub of each design parameter at a distance of $\alpha$ from the design center. And the third segment is $n_{o}$ center focuses. So, the total number of design points in a CCD may be evaluated by (39).

$$
n=2^{k}+2 k+n_{o}
$$

Taguchi's approach: The design parameters of any process can be classified as control parameters (which are easy to control) and the noise parameters (which are difficult to control). The noise factors are the reason behind numerous output responses. The fundamental point of parameter configuration is to decide the settings of the control factors for which the procedure reaction is robust to the inconstancy in the framework brought about by the noise factors. To accomplish this objective, Genichi Taguchi advocated the use of crossed arrays by crossing an orthogonal array of control variables (internal array) with an orthogonal array of noise variables (external array) (Khuri and Mukhopadhyay 2010). Taguchi identified three specific goals (minimize, maximize, or achieve the target value of the response) in a process and defined them with a signal-to-noise ratio $(S / N)$. This $S / N$ performance criteria (considering both processes mean and variance) can be expressed as: 


$$
\left.\begin{array}{c}
\text { Minimize } S / N:-10 \log \left[\frac{1}{n} \sum_{i=0}^{n} y_{i}^{2}\right] \\
\text { Maximize } S / N:-10 \log \left[\frac{1}{n} \sum_{i=0}^{n} \frac{1}{y_{i}^{2}}\right] \\
\text { Target } S / N:-10 \log \left[\sum_{i=0}^{n} \frac{s^{2}}{\bar{y}_{i}^{2}}\right]
\end{array}\right\}
$$

where $\bar{y}$ and $s^{2}$ are the sample mean and variance, respectively.

\subsubsection{Design parameters and responses}

As per the Taguchi's approach, for the mathematical modeling of the $2^{\text {nd }}$ order RSM methodology, design parameters are considered as: number of charging points (NCP), the investment required for setting up HCS (HCSI), energy tariffs (TR), and plug-in-period (PIP). The objective of the proposed charging strategy is to find the optimal location of charging stations along the plying route such that the total travel time, including driving time from current location to destination HCS, waiting and charging time at HCS and the charging cost are minimized while capacities of the HCSs are fully utilized. To achieve the above objective, the responses considered are: power requirement $(P R)$, total system losses (TSL), and battery life $(B L)$.

\subsubsection{Mathematical modeling}

The second order model for responses PR, TSL, and BL are recognized from the optimal sizing of HCS response achieved by considering CCD given in Table 4. The central value of design parameters for the sizing of HCS conforming to code ' 0 ' are the optimum design parameters for the sizing of HCS obtained from Taguchi's multi-objective optimization methodology. Here, the coded values for CCD at diverse levels are $-2,-1,0,1$, and 2 .

Table 4 Coded level of design parameters for sizing of HCS and their values

\begin{tabular}{lllllll}
\hline Input parameters & Symbol & \multicolumn{2}{l}{ Coded Levels } \\
\cline { 3 - 7 } & & -2 & -1 & 0 & 1 & 2 \\
\hline No. of charging points & NCP & 5 & 10 & 15 & 20 & 25 \\
HCS investment & HCSI & 4.43 & 26.59 & 48.75 & 80.01 & 134.04 \\
Tariff & TR & 0.432 & 1.908 & 2.736 & 3.339 & 4.482 \\
Plug-in period & PIP & 5 & 15 & 25 & 35 & 50 \\
\hline
\end{tabular}

The outcomes acquired from $\mathrm{C}++$ code composed for sizing of HCS and in the wake of executing CCD were expressed in Table 5 as RSM L31 design matrix.

Table 5 L31 design Matrix

\begin{tabular}{llllllll}
\hline Exp. Run & NCP & HCSI (million ₹) & TR (million ₹) & PIP (min) & PR (MW) & TSL (MW) & BL (Yr) \\
\hline 1 & 20 & 80.01 & 3.339 & 35 & 16.73 & 0.828339 & 4.01 \\
2 & 15 & 48.75 & 2.736 & 25 & 3.76 & 0.256164 & 4.58 \\
3 & 15 & 48.75 & 2.736 & 25 & 3.76 & 0.256164 & 4.58 \\
4 & 15 & 48.75 & 4.482 & 25 & 9.12 & 0.526806 & 4.37 \\
5 & 20 & 26.59 & 3.339 & 15 & 5.29 & 0.370335 & 4.68 \\
6 & 10 & 26.59 & 3.339 & 15 & 0.79 & 0.217092 & 4.91 \\
7 & 20 & 80.01 & 3.339 & 15 & 9.79 & 0.523569 & 4.45 \\
8 & 10 & 26.59 & 1.908 & 35 & 2.57 & 0.357344 & 4.94 \\
9 & 10 & 26.59 & 3.339 & 15 & 0.79 & 0.217092 & 4.91 \\
10 & 15 & 48.75 & 2.736 & 5 & 0.12 & 0.190318 & 5 \\
11 & 15 & 48.75 & 2.736 & 25 & 3.76 & 0.256164 & 4.58 \\
12 & 15 & 48.75 & 0.432 & 25 & 0.12 & 0.190318 & 5 \\
13 & 10 & 80.01 & 1.908 & 35 & 7.07 & 0.510578 & 4.71 \\
14 & 15 & 48.75 & 2.736 & 25 & 3.76 & 0.256164 & 4.58 \\
15 & 15 & 48.75 & 2.736 & 50 & 11.27 & 0.699134 & 4.21 \\
16 & 20 & 80.01 & 1.908 & 15 & 4.63 & 0.359051 & 4.92 \\
17 & 10 & 80.01 & 3.339 & 35 & 12.23 & 0.675096 & 4.24 \\
\hline
\end{tabular}




\begin{tabular}{llllllll}
\hline 18 & 5 & 48.75 & 2.736 & 25 & 0.12 & 0.190318 & 5 \\
19 & 10 & 80.01 & 3.339 & 15 & 5.29 & 0.370326 & 4.68 \\
20 & 15 & 4.43 & 2.736 & 25 & 0.12 & 0.190318 & 5 \\
21 & 15 & 134.04 & 2.736 & 25 & 11.27 & 0.699134 & 4.21 \\
22 & 10 & 26.59 & 3.339 & 35 & 7.73 & 0.521862 & 4.47 \\
23 & 15 & 48.75 & 2.736 & 25 & 3.76 & 0.256164 & 4.58 \\
24 & 15 & 48.75 & 2.736 & 25 & 3.76 & 0.256164 & 4.58 \\
25 & 20 & 26.59 & 1.908 & 35 & 7.07 & 0.510587 & 4.71 \\
26 & 20 & 80.01 & 1.908 & 35 & 11.57 & 0.663821 & 4.48 \\
27 & 20 & 26.59 & 3.339 & 35 & 12.23 & 0.675105 & 4.24 \\
28 & 10 & 80.01 & 1.908 & 15 & 0.13 & 0.205808 & 5 \\
29 & 15 & 48.75 & 2.736 & 25 & 3.76 & 0.256164 & 4.58 \\
30 & 20 & 26.59 & 1.908 & 15 & 0.13 & 0.205817 & 5 \\
31 & 25 & 48.75 & 2.736 & 25 & 11.27 & 0.699134 & 4.21 \\
\hline
\end{tabular}

The design matrix was created with the assistance of MINITAB 17, comprising of a full factorial plan including 31 most appropriate combinations. Analysis of variance (AOV) was utilized to break down the model and foresee the noteworthiness of every parameter considered for the examination, and the aftereffect of the created models are shown in Tables 6-8.

Table 6 Analysis of Variance for BL developed under RSM model

\begin{tabular}{llllll}
\hline \multirow{2}{*}{ Source } & \multicolumn{3}{l}{ Battery Life } & & \\
\cline { 2 - 6 } & DF & Adj SS & Adj MS & F-Value & P-Value \\
\hline Regression & 4 & 2.57190 & 0.64297 & 65.91 & 0.000 \\
NCP & 1 & 0.45028 & 0.45028 & 46.15 & 0.000 \\
HCSI (million ₹) & 1 & 0.44693 & 0.44693 & 45.81 & 0.000 \\
TR (million ₹) & 1 & 0.94568 & 0.94568 & 96.93 & 0.000 \\
PIP (Min.) & 1 & 1.02313 & 1.02313 & 104.87 & 0.000 \\
Error & 26 & 0.25366 & 0.00976 & & \\
Lack-of-Fit & 19 & 0.25366 & 0.01335 & & \\
Pure Error & 7 & 0.00000 & 0.00000 & & \\
Total & 30 & 2.82555 & & & \\
\hline
\end{tabular}

Table 7 Analysis of Variance for TSL developed under RSM model

\begin{tabular}{llllll}
\hline \multirow{2}{*}{ Source } & \multicolumn{5}{l}{ Total System Losses } \\
\cline { 2 - 6 } & DF & Adj SS & Adj MS & F-Value & P-Value \\
\hline Regression & 4 & 1.00950 & 0.252375 & 32.43 & 0.000 \\
NCP & 1 & 0.20446 & 0.204455 & 26.28 & 0.000 \\
HCSI (million ₹) & 1 & 0.24243 & 0.242433 & 31.16 & 0.000 \\
TR (million ₹) & 1 & 0.15912 & 0.159118 & 20.45 & 0.000 \\
PIP (Min.) & 1 & 0.48819 & 0.488193 & 62.74 & 0.000 \\
Error & 26 & 0.20231 & 0.007781 & & \\
Lack-of-Fit & 19 & 0.20231 & 0.010648 & & \\
Pure Error & 7 & 0.00000 & 0.000000 & & \\
Total & 30 & 1.21181 & & & \\
\hline
\end{tabular}

Table 8 Analysis of Variance for PR developed under RSM model

\begin{tabular}{llllll}
\hline & \multicolumn{3}{l}{ Power Required } & & \\
\cline { 2 - 6 } Source & DF & Adj SS & Adj MS & F-Value & P-Value \\
\hline Regression & 4 & 594.717 & 148.679 & 80.18 & 0.000 \\
NCP & 1 & 135.758 & 135.758 & 73.21 & 0.000 \\
HCSI (million ₹) & 1 & 144.131 & 144.131 & 77.72 & 0.000 \\
TR (million ₹) & 1 & 132.191 & 132.191 & 71.29 & 0.000 \\
PIP (Min.) & 1 & 240.880 & 240.880 & 129.90 & 0.000 \\
Error & 26 & 48.214 & 1.854 & & \\
Lack-of-Fit & 19 & 48.214 & 2.538 & & \\
Pure Error & 7 & 0.000 & 0.000 & & \\
Total & 30 & 642.931 & & & \\
\hline
\end{tabular}


Additionally, the regression conditions for each response are given as under by (Eqs. (41)-(43)).

Power Requirement (MW)

$$
\begin{aligned}
& =-9.2-0.426 \mathrm{NCP}+0.0442 \mathrm{HCSI}+0.25 \mathrm{TR}+0.135 \mathrm{PIP}+0.0279 \mathrm{NCP} \times \mathrm{NCP} \\
& +0.000128 \mathrm{HCSI} \times \mathrm{HCSI}+0.496 \mathrm{TR} \times \mathrm{TR}+0.00284 \mathrm{PIP} \times \mathrm{PIP}+0.00021 \mathrm{NCP} \\
& \times \mathrm{HCSI}+0.009 \mathrm{NCP} \times \mathrm{TR}+0.00124 \mathrm{NCP} \times \mathrm{PIP}+0.0034 \mathrm{HCSI} \times \mathrm{TR}+0.00050 \mathrm{HCSI} \times \mathrm{PIP} \\
& -0.0089 \mathrm{TR} \times \mathrm{PIP}
\end{aligned}
$$

Total System Losses (MW)

$$
\begin{aligned}
& =0.183-0.0471 \mathrm{NCP}-0.00014 \mathrm{HCSI}-0.041 \mathrm{TR}-0.0009 P I P+0.002268 \mathrm{NCP} \times \mathrm{NCP} \\
& +0.000032 \mathrm{HCSI} \times \mathrm{HCSI}+0.0345 \mathrm{TR} \times \mathrm{TR}+0.000322 \mathrm{PIP} \times \mathrm{PIP}-0.000024 \mathrm{NCP} \\
& \times \mathrm{HCSI}-0.00028 \mathrm{NCP} \times \mathrm{TR}-0.000008 \mathrm{NCP} \times \mathrm{PIP} \\
& -0.000124 \mathrm{HCSI} \times \mathrm{TR}+0.000012 \mathrm{HCSI} \times \mathrm{PIP}-0.00098 \mathrm{TR} \times \mathrm{PIP}
\end{aligned}
$$

$$
\begin{aligned}
& \text { Battery Life (Years) } \\
& =6.089-0.0200 \mathrm{NCP}-0.00145 \mathrm{HCSI}-0.109 \mathrm{TR}-0.0193 \mathrm{PIP}+0.000386 \mathrm{NCP} \times \mathrm{NCP} \\
& +0.000016 \text { HCSI } \times \text { HCSI }+0.0000 \text { TR } \times \text { TR }+0.000165 \text { PIP } \times \text { PIP }-0.000055 \text { NCP } \\
& \times \text { HCSI }-0.00346 \text { NCP } \times \text { TR }-0.000255 \text { NCP } \times \text { PIP }-0.00112 \text { HCSI } \times \text { TR }-0.000053 \text { HCSI } \times \text { PIP } \\
& \text { - } 0.00087 \text { TR } \times \text { PIP }
\end{aligned}
$$

The genuine issues need enhancement with various responses of intrigue. The present work embraces procedures, for example, plotting surface plots for each response with two design parameters while keeping the other two at hold; constrained enhancement and attractive quality methodology. The present work utilizes RSM-based quality methodology for doing enhancement of measuring of HCS parameters (BL, TSL, and PR) for choosing the optimal number of charging technology ports for EB load. The streamlining investigation is done by utilizing MINITAB 17 software, where each response is changed to dimensionless desirability significance $(D D S)$, and its worth ranges between $0 \leq D D S \leq 1$. These qualities show that $D D S=0$ represents a totally unsuitable reaction while $D D S=1$ represents progressively attractive reactions. The condition of desirability is given for both bigger-the-better $(B T B)$ and smaller-the-better $(S T B)$ kinds of reaction, which are mathematically expressed as:

$$
\begin{aligned}
& D D S_{B T B}=\left\{\begin{array}{lr}
\left|\frac{y-L D L}{U D L-L D L}\right|^{S} L D L \leq y \leq U D L \\
0, & y<L D L \\
1, & y>U D L
\end{array}\right. \\
& D D S_{S T B}=\left\{\begin{array}{lr}
\left|\frac{y-L D L}{a-L D L}\right|^{t} & a \leq y \leq U D L \\
0, & y>U D L
\end{array}\right.
\end{aligned}
$$

where $s$ and $t$ are the shape constants exponents, $L D L$ and $U D L$ are lower and upper design limits (' $a$ ' is the lowest conceivable incentive for response $y$ ). After getting the most appropriate combinations according to the design matrix, AOV was calculated, which offers the numerical data about the $p$-value. The $p$-value is characterized as the option in contrast to the elimination points to give the littlest degree of significance at which the invalid speculation would be dismissed. The greatest estimation of $p$ is taken as 0.05 , and the $p$-values $>0.05$ are considered unimportant.

To check suitability of the created model for the acquired data, the $S$-value is calculated from the regression analysis for each response BL, TSL, and PR, which are 0.0988, 0.0882, and 1.3618 respectively, which are the lowest. $R^{2}$ value for the three responses are $91.02 \%, 83.31 \%$, and $92.5 \%$, respectively, and $R^{2}(a d j)$-values are $89.64 \%, 80.74 \%$ and $91.35 \%$ respectively. These values indicate that the applied model fits well with the acquired data.

\section{Results and discussion}

After performing load flow analysis on 69-node IEEE modified distribution test system in MATLAB R2017a environment and financial analysis on considered configurations for optimal siting of HCS, the results for optimal sizing of HCS using RSM are carried out in the present work. The following sub-sections present the results of the above analysis, i.e., the calculated results of the impact of design parameters (NCP, HCSI, TR, and PIP) on output responses (PR, TSL, and BL) of the optimization process with RSM and, finally, the results obtained from RSM are verified with those of the calculated results. The results are depicted with the help of surface plots for output responses. These surface plots relate one response with two design parameters (out of four) at a time while keeping the rest of the two design parameters constant. These hold values are the central value of the CCD Table. As per Table 2, after calculation, a total of 3241 responses are obtained, whose summary is presented in Table 3.

The optimized location for sitting of HCS comes out to be nodes 17, 18, or 19. In the following subsections, the results obtained from RSM are discussed.

\subsection{Effect of design parameters on power requirement (PR)}

Figure 4 presents the surface plots of variation in PR with the change in various design parameters. 


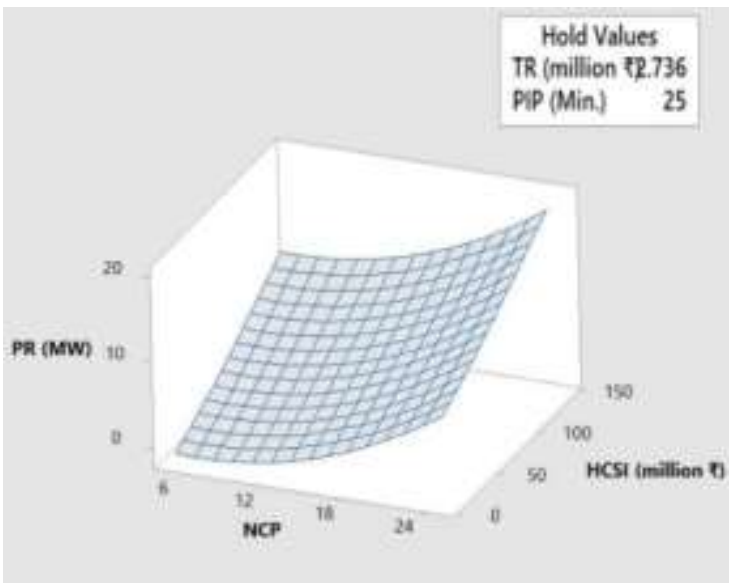

(a)

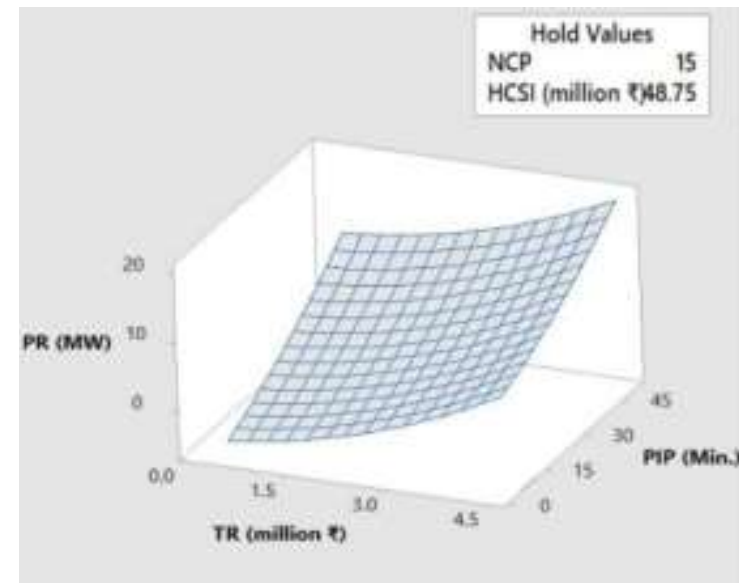

(b)

Fig. 4 Surface plot of response PR versus design parameters (a) PR versus HCSI and NCP, (b) PR versus PIP and TR

Figure 4a represents the effect of NCP and HCSI on PR while keeping TR and PIP at hold values of ₹ 2.736 million and 25 min, respectively, which shows that PR increases with an increase in NCP as well as HCSI. Initially, the change in PR is gradual with the variation of NCP as in the beginning; the charging ports configurations are based on BST ports. BST ports require less power for operation as compared to that of the other two technologies. After NCP reaches a value of 12, the variation in PR increases exponentially because, for a higher value of NCP, the FCT and the UFCT ports dominate over BST ports. It can also be seen from Figure $3 a$ that the PR varies almost linearly with HCSI. Figure $4 \mathbf{b}$ shows the effect of TR and PIP on PR while HCSI and NCP are kept at hold (₹ 48.75 $\mathrm{M}$ and 15, respectively). It is evident from the curve that there is an exponential increase in PR with the increase in PIP since, as compared to BST ports, an increase in FCT and UFCT ports will sharply increase PR, and also will take more plug-in time due to their charging characteristics. Similar relations are obtained when the combinations of design parameters are changes. The trends show that PR has an almost linear and increasing relationship with all four design parameters. This indicates how the power requirement for various technology ports will increase with an increase in all four design parameters.

\subsection{Effect of design parameters on total system losses}

Figure 5 depicts the effect on TSL with variation in design parameters. Figure 5a shows the variation of TSL with NCP and HCSI while keeping the other two design parameters constant (hold). The trend shows a slight reduction in TSL initially and then a considerable increase in losses as NCP increases further. This tendency is validated by the fact that in the beginning, the number of BST ports is less, the FCT and UFCT ports dominate, and hence the PR increases exponentially. Later, with changing configurations, the number of BST ports increases (hence the number of the FCT and UFCT ports decrease), while the PR decreases. The required investment increases when the number of FCT and UFCT ports increases. Along with the investment, losses increase as well, as they consume bulk power, whereas the BST requires normal power for long-duration charging of spare battery packs. The plug-in period also increases with higher penetration of these two technologies and, hence, after a slight dip in losses initially, those increase with an increase in PIP (Figure 5b). These sub-plots clearly show that TSL value increases with an increase in TR and attains a peak value when all the ports considered are of UFCT type while HCSI and PIP are kept at hold. Total system losses have the same trend as that of power requirement, and that is because those have a positive correlation.

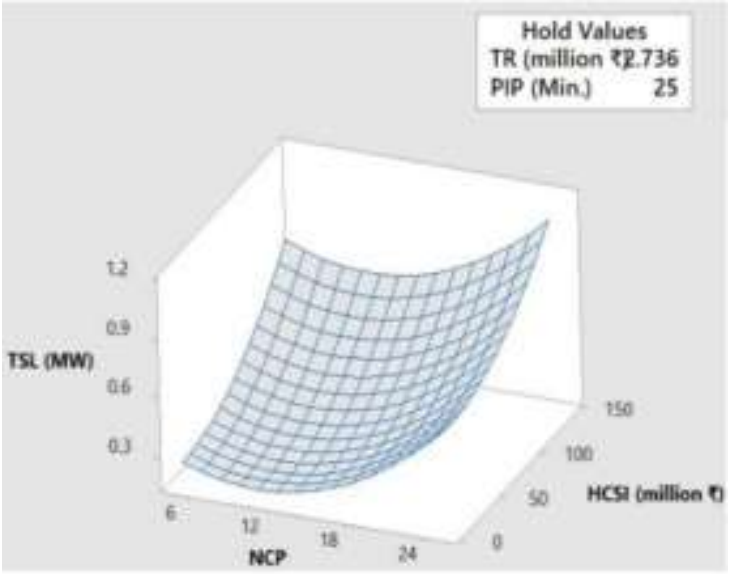

(a)

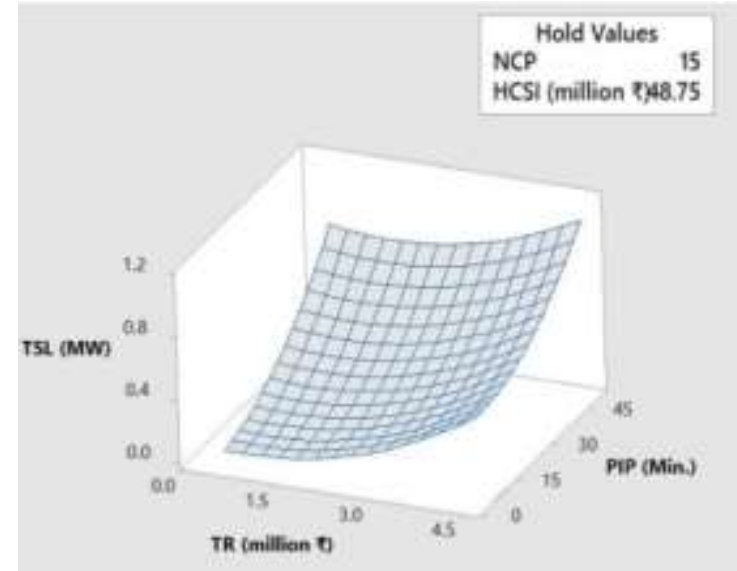

(b)

Fig. 5 Surface plot of response TSL versus design parameters (a) TSL versus HCSI and NCP (b) TSL versus PIP and TR

\subsection{Effect of design parameters on battery life}

Figure 6 shows the graphical plot of BL with the change in various design parameters. It may be noted from Figure $6 \mathbf{a}$ that BL value monotonously decreases with an increase in both NCP and HCSI, from an initial peak value, and attains minimum value at maximum $\mathrm{NCP}$ and HCSI. The reason behind this nature of the plot is that BL is maximum in the case of BST and minimum in the rest of the two charging technology. The same trend is noted for the variation of BL with PIP (Figure 6b). Although there is no direct relation of 
TR with BL, even though indirectly, the BL decreases with an increase in TR. It may be concluded from the results that except for BST ports, all other fast chargers will decrease the life of the battery, whether it is a spare one; or the one mounted on EBs.

The battery life is observed to decrease with an increase in PIP and with more usage, apart from an increase in the number of FCT or UFCT ports. It is high initially for all the cases because the initial port configuration consists of BST ports which charge spare battery packs with least charging power and in a maximum allowable time frame.

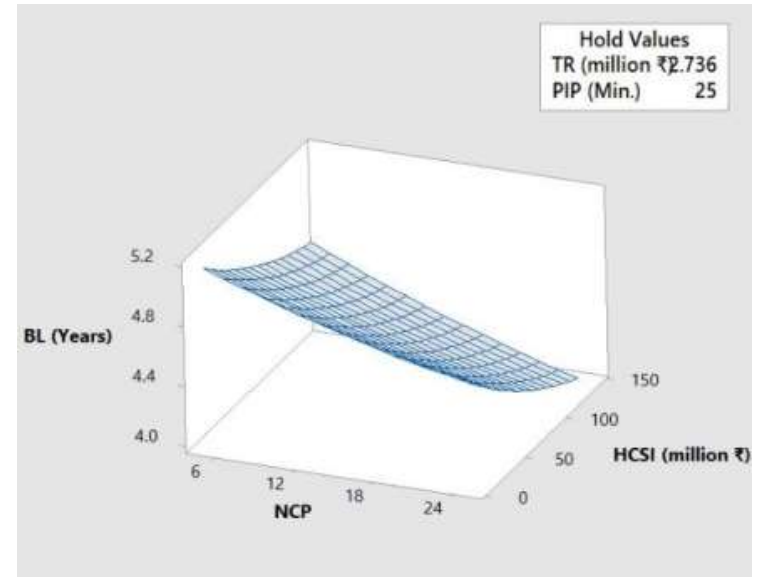

(a)

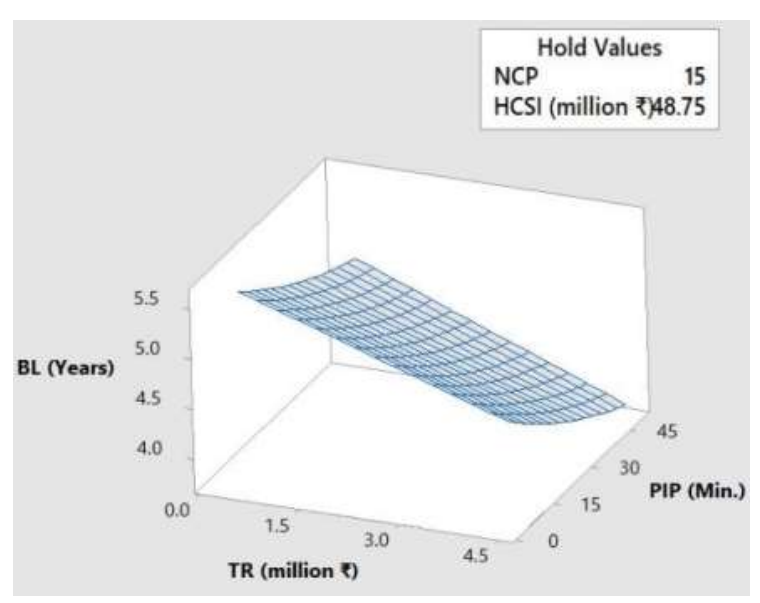

(b)

Fig. 6 Surface plot of response BL versus design parameters (a) BL versus HCSI and NCP, (b) BL versus PIP and TR

\subsection{Optimization reaction}

The present study primarily focuses on optimizing the sitting and sizing of HCS through the application of the RSM technique. The results obtained through the analysis are summarized in Figure 7.

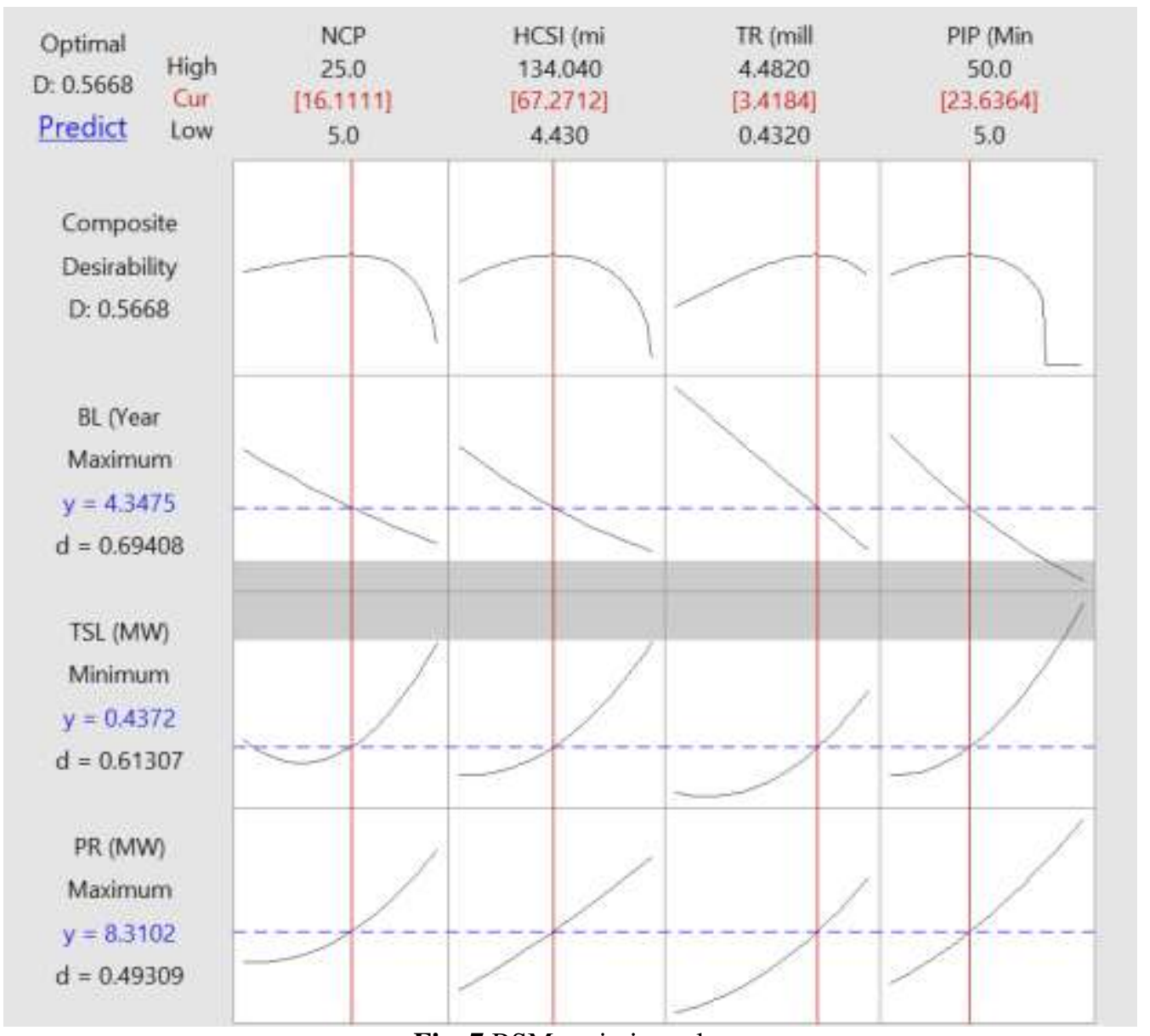

Fig. 7 RSM optimizer plot

Optimum values obtained for various input design parameters are NCP of 16.11 numbers, HCSI of ₹ 67.2712 M, TR of ₹ 3.4184 M, PIP of 23.6364 minutes, and the optimum values of output responses obtained are PR of 8.3102 MW, TSL of 0.4372 MW, and BL of 4.3475 years. 


\subsection{Validation of results}

The results obtained from RSM are compared with the responses attained from the DSM calculations, and the closest ones are shown in Table 9. Table 10 presents results justification with percentage variation to the optimized design parameters and output response values obtained from the RSM optimizer.

Table 9 Closest responses attained from calculated result to RSM

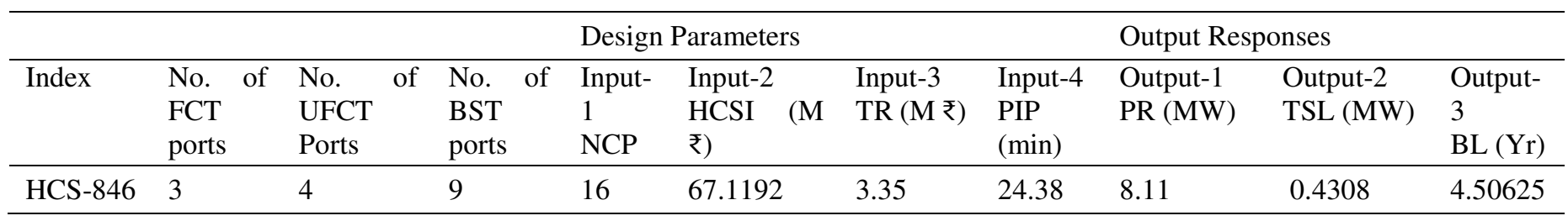

Table 10 Validation test of RSM optimize results with calculated values

\begin{tabular}{|c|c|c|c|c|c|}
\hline Design parameters & Notation & Units & $\begin{array}{l}\text { Predicted } \\
\text { (RSM) }\end{array}$ & $\begin{array}{l}\text { Actual } \\
\text { Calculated } \\
\text { (DSM) }\end{array}$ & $\%$ Variation \\
\hline No. of CP & $\mathrm{NCP}$ & & 16 & 16 & 0 \\
\hline HCS investment & HCSI & $M ₹$ & 67.2712 & 67.1192 & -0.23 \\
\hline Tariff & $\mathrm{TR}$ & M ₹ & 3.4184 & 3.35 & -2.06 \\
\hline Plug-in period & PIP & $\min$ & 23.6364 & 24.38 & +3.04 \\
\hline \multicolumn{6}{|l|}{ Output responses } \\
\hline Power requirement & PR & MW & 8.3102 & 8.11 & -2.46 \\
\hline Total system losses & TSL & MW & 0.4372 & 0.4308 & -1.49 \\
\hline Battery life & $\mathrm{BL}$ & $\mathrm{Yr}$ & 4.3475 & 4.50625 & +3.52 \\
\hline
\end{tabular}

The \% variation for the optimal sitting and sizing of HCS response parameters PR (MW), TSL (MW), BL (Yr) are 2.46\%, 1.49\%, and $3.52 \%$, respectively, and all are well within limits. This indicates that RSM methodology can be adopted for the prediction of bestsuited HCS sizing input parameters for optimized performance responses. Out of a total of 3241 calculated responses, the closest and optimal solution provided by RSM is of 16 charging ports (consist of 3 FCT ports, 4 UFCT ports, and 9 BST ports). The best location for the optimal sitting of HCS comes out to be at nodes 17, 18, and 19 (see Figure 8) with a minimum voltage of 0.921 p.u. at node 57.

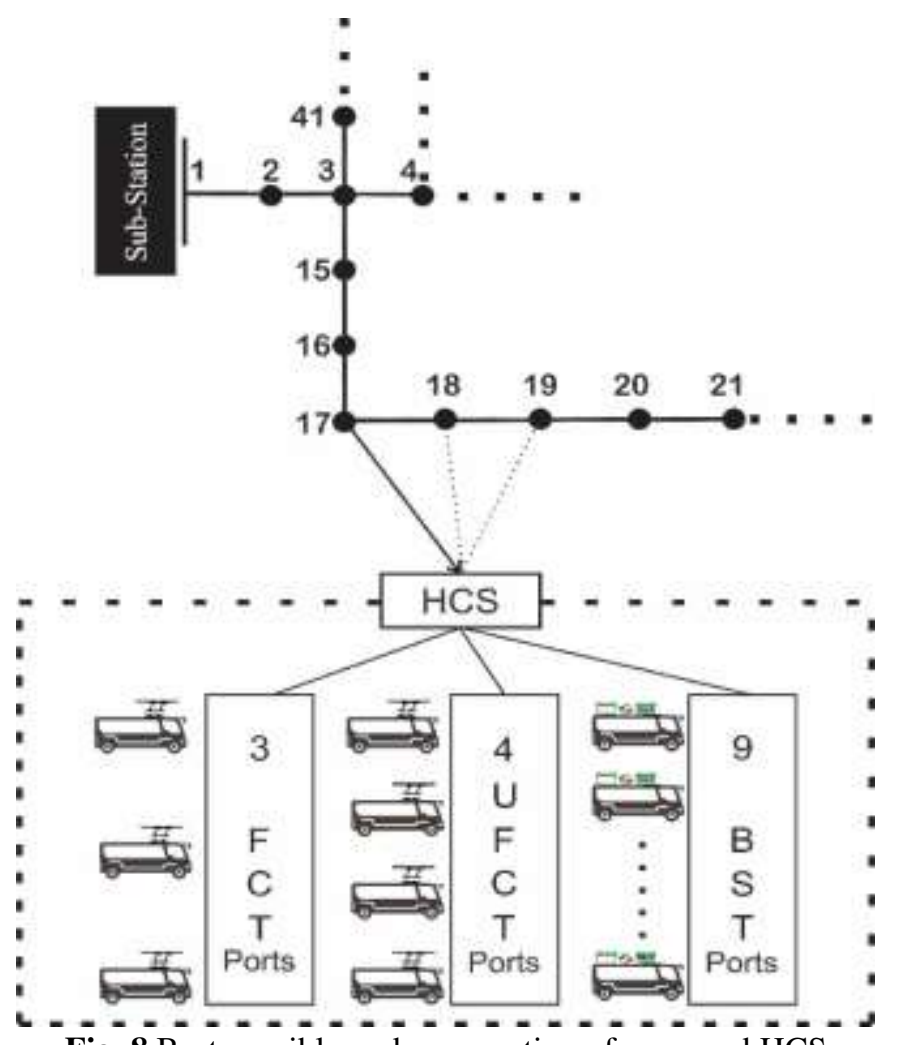

Fig. 8 Best possible node connection of purposed HCS

\section{Conclusion}

Faster adoption of EVs and EBs will help the global community deal with environmental pollution and climate change. However, this will also put additional stress on the distribution network. Hence, DNEP will be of paramount importance as the penetration of EVs 
and EBs increases. A novel technique is proposed in this paper for solving the DNEP problem, considering the integration of parent and host charging stations. In the proposed model, various parameters such as number charging port, types of charging technology, and power requirements are optimized under the predetermined constraints of voltage fluctuation, minimization of losses, and plug-inperiod. It can be concluded from the analysis that BST is the most efficient option in all considered charging ports categories' permutations and combinations. However, under practical constraints, when a combination of technologies is to be used, an entwined network of a low number of FCT and UFCT with maximum counts of BST emerges to be best suited. Out of a total of 3241 calculated responses, the closest and optimal solution provided by RSM is of 16 charging ports (consist of 3 FCT ports, 4 UFCT ports, and 9 BST ports). The best location for the optimal sitting of HCS comes out to be at nodes 17, 18, and 19 with a minimum voltage of 0.921 p.u. at node 57.

The methodology can be implemented considering the projected requirement to meet future demand. By keeping two out of four design parameters non-variable (fixed at mid-point value), the methodology presents the variation of each response with the other two variable design parameters. The results provide a vast field of choices to the HCS planner to choose and prioritize design parameters. As a case study, data of the city of Delhi, India, is used in the present work. The proposed methodology can help the planner to prioritize and integrate a significant number of charging points of different technologies into the distribution network without adversely affecting its reliability, stability, and performance.

As a scope of future work, the proposed model can be further improved by considering the following.

(a) Re-compute a fresh power assignment profile during the day itself, considering the personal and commercial EV charging at night.

(b) In highly polluted cities like New Delhi, India, to reduce the impact on the environment further, the power generation for charging stations may be from renewable energy sources.

(c) The spare capacity of the HCS can be utilized for private and commercial EV charging.

(d) The temperature variation factor has not been considered in the present work, which can be included in future work.

\section{Compliance with ethical standards}

Conflict of interest The authors declare that they have no conflict of interest.

Ethical approval The article does not contain any studies with human participants or animals performed by any of the authors.

\section{References}

An K, Jing W, Kim I (2019) Battery-swapping facility planning for electric buses with local charging systems. International Journal of Sustainable Transportation 13:1-13 https://doi.org/10.1080/15568318.2019.1573939

Box GEP, Wilson KB (1951) On the Experimental Attainment of Optimum Conditions. Journal of the Royal Statistical Society 13(1):145 https://www.jstor.org/stable/2983966

Bessa RJ, Matos MA (2013) Global against divided optimization for the participation of an EV aggregator in the day-ahead electricity market Part II: numerical analysis. Electrical Power System Research 95:319-329 https://doi.org/10.1016/j.epsr.2012.08.013

Bayram IS, Michailidis G, Devetsikiotis M, Granelli F (2013) Electric Power Allocation in a Network of Fast Charging Stations. IEEE Journal on Selected Areas in Communications 31(7):1235-1246 https://doi.org/10.1109/JSAC.2013.130707

Battapothula G, Yammani C, Maheswarapu S (2019) Multi-objective simultaneous optimal planning of electrical vehicle fast charging stations and DGs in distribution system. J. Mod. Power Syst. Clean Energy 7:923-34. https://doi.org/10.1007/s40565-018-0493-2

Chen T et al. (2020) A review on electric vehicle charging infrastructure development in the UK. Journal of Modern Power Systems and Clean Energy 8(2):193-205. 10.35833/MPCE.2018.000374

Dong X, Mu Y, Xu X et al. (2018) A charging pricing strategy of electric vehicle fast charging stations for the voltage control of electricity distribution networks. Applied Energy 225:857-868 https://doi.org/10.1016/j.apenergy.2018.05.042

DERC (Delhi Electricity Regulatory Commission) 2019. "Press Note for Electricity Tariff For FY 2019-20". Accessed 16 October 2019. http://www.derc.gov.in/Press_Release/Press_Release_31.07.2019/Press_release.pdf

DHI FAME-II (Department of Heavy Industry- Faster Adoption and Manufacturing of Electric Vehicles in India Phase II) 2019. "Expression of interest inviting proposals for availing incentives under Fame India scheme phase II for deployment of EV charging infrastructure within cities." Accessed 12 September 2019. https://dhi.nic.in/writereaddata/UploadFile/Revised$\% 20$ Expression $\% 20$ of\%20Interest.pdf

Ekren O, Ekren BY (2008) Size optimization of a PV/wind hybrid energy conversion system with battery storage using response surface methodology. Applied Energy 85(11):1086-1101. https://doi.org/10.1016/j.apenergy.2008.02.016

Gomez J, Morcos M (2002) Impact of EV Battery Chargers on the Power Quality of Distribution Systems. IEEE Power Engineering Review 22(10):63 https://doi.org/10.1109/TPWRD.2003.813873

Galus MD, Waraich RA, Noembrini F et al. (2012) Integrating power systems, transport systems and vehicle technology for electric mobility impact assessment and efficient control. IEEE Transections on Smart Grid 3(2):934-949. https://doi.org/10.1109/TSG.2012.2190628

Ghosh S, Yadav VK, Mehta G, Birajdar R (2017) Evaluation of Indian power sector reform strategies and improvement direction though DEA. IEEE Power \& Energy Society General Meeting, Chicago, IL, 2017, pp. 1-5.

Ghosh S, Yadav R (2021) Future of Photovoltaic Technologies: A Comprehensive Review, Sustainable Energy Technologies and Assessments 47:101410. https://doi.org/10.1016/j.seta.2021.101410.

GoI-MoP (Government of India-Ministry of Power) 2018. "Charging Infrastructure for Electric Vehicles-Guidelines and Standards reg." Accessed 31 October 2019. https://powermin.nic.in/sites/default/files/webform/notices/scan0016\%20\%281\%29.pdf

Haesen E, Bastiaensen C, Driesen J, Belmans R (2009) A probabilistic formulation of load margins in power systems with stochastic generation. IEEE Transactions on Power Systems 24(2):951-958. https://doi.org/10.1109/TPWRS.2009.2016525 
Hadley SW, Tsvetkova AA (2009) Potential impacts of plug-in hybrid electric vehicles on regional power generation. The Electricity Journal 22(10):56-68. https://doi.org/10.1016/j.tej.2009.10.011

Hasanien HM, Muyeen SM (2013) A Taguchi Approach for Optimum Design of Proportional-Integral Controllers in Cascaded Control Scheme. IEEE Transactions on Power Systems 28(2):1636-1644 https://doi.org/10.1109/TPWRS.2012.2224385

Jeon K, Chung T, Hahn S (2011) NEMA class a slot shape optimization of induction motor for electric vehicle using response surface method. International Conference on Electrical Machines and Systems, Beijing, $2011,1-4$. https://doi.org/10.1109/ICEMS.2011.6073692

Jingwei Y, Diansheng L, Shuang Y, Shiyu H (2014) Charging Load Forecasting for Electric Vehicles Based on Fuzzy Inference. Communications in Computer and Information Science, Springer 484:585-594. https://doi.org/10.1007/978-3-662-45643-9_62

Jafari M, Gauchia A, Zhao S, Zhang K, Gauchia L (2018) Electric Vehicle Battery Cycle Aging Evaluation in Real-World Daily Driving and Vehicle-to-Grid Services. IEEE Transactions on Transportation Electrification 4(1):122-134 https://doi.org/10.1109/TTE.2017.2764320

Khuri AI, Mukhopadhyay S (2010) Response surface methodology. Wires Computational Statistics 2(2):128-149 https://doi.org/10.1002/wics.73

Karfopoulos EL, Hatziargyriou ND (2013) A multi-agent system for controlled charging of a large population of electric vehicles. IEEE Transections on Power Systems 28(2):1196-1204 https://doi.org/10.1109/TPWRS.2012.2211624

Li H, Bai X (2011) Impacts of electric vehicles charging on distribution grid. Automation of Electric Power Systems 35(17):38-43

Muratori M, Elgqvist E, Cutler D, et al. (2019) Technology solutions to mitigate electricity cost for electric vehicle DC fast charging. Applied Energy 242:415-423 https://doi.org/10.1016/j.apenergy.2019.03.061

Nicolaides D et al. (2019) Technoeconomic analysis of charging and heating options for an electric bus service in London. IEEE Transactions on Transportation Electrification 5(3):769-781. 10.1109/TTE.2019.2934356

Pillai RK, Suri R, Kundu S, Singh H, Roy SS, Dhuri S (2018) Electric Vehicle Charging Stations Business Models for India. India Smart Grid Forum (ISGF) White Paper 1-15. accessed $15 \quad$ August 2019 http://www.indiasmartgrid.org/reports/ISGF_White_Paper_-_EVSE_Business_Models_for_India.pdf

Richardson P, Flynn D, Keane A (2012) Optimal charging of electric vehicles in low-voltage distribution systems. IEEE Transactions on Power System 27(1):268-279. https://doi.org/10.1109/TPWRS.2011.2158247

Ren Z, Li W, Billinton R, Yan W (2016) Probabilistic Power Flow Analysis Based on the Stochastic Response Surface Method. IEEE Transactions on Power Systems 31(3):2307-2315. https://doi.org/10.1109/TPWRS.2015.2461159

Savier JS, Das D (2007) Impact of network reconfiguration on loss allocation of radial distribution systems. IEEE Transactions on Power Delivery 22(4):2473-2480. https://doi.org/10.1109/TPWRD.2007.905370

Shao S, Pipattanasomporn M, Rahman S (2009) Challenges of PHEV penetration to the residential distribution network. Power \& Energy Society General Meeting (PESGM'2009), Calgary AB Canada, 1-8. https://doi.org/10.1109/PES.2009.5275806

TET (The Economics Times) (2015). "Rs 10-crore electric bus pilot in final leg; PM to gift two to ferry MPs." Accessed 1 June 2019. https://economictimes.indiatimes.com/industry/transportation/rs-10-crore-electric-bus-pilot-in-final-leg-pm-to-gift-two-to-ferrymps/articleshow/50235921.cms?from $=$ mdr.

Tang D, Wang P (2016) Probabilistic modeling of nodal charging demand based on spatial-temporal dynamics of moving electric vehicles. IEEE Transections on Smart Grid 7(2):627-636. https://doi.org/10.1109/TSG.2015.2437415

TGOI (The Gazette of India). 2019. "Scheme for Faster Adoption and Manufacturing of Electric Vehicles in India Phase II (FAME India Phase II)." Part II, Section 3, Sub-section (ii). India: Department of Heavy Industry. https://dhi.nic.in/writereaddata/UploadFile/DHI_FAMEII_Gazette.pdf

Verma MK, Mukherjee V, Yadav VK, (2016) Greenfield distribution network expansion strategy with hierarchical GA and MCDEA under uncertainty. Electrical Power and Energy Systems 79:245-252. https://doi.org/10.1016/j.ijepes.2016.01.004

Verma, MK, Yadav, VK, Mukherjee, V, Ghosh, S (2019) A Multi-criteria Approach for Distribution Network Expansion Through Pooled MCDEA and Shannon Entropy. International Journal of Emerging Electric Power Systems 20(4):245-252. https://doi.org/10.1515/ijeeps-2019-0043

Wang Y, Chiang H, Wang T (2013) A two-stage method for assessment of voltage stability in power system with renewable energy. In: IEEE Electrical Power and Energy Conference, pp 1-6. https://doi.org/10.1109/EPEC.2013.6802933

Wei X, Lin L, Yue X, et al. (2016) Optimal allocation for charging piles in multi-areas considering charging load forecasting based on Markov chain. In: China International Conference on Electricity Distribution (CICED), Xi'an, pp 1-7. https://doi.org/10.1109/CICED.2016.7576277

Wang F, Xiao X, Sun Q, et al. (2019) Service restoration for distribution network with DGs based on stochastic response surface method. International Journal of Electrical Power and Energy Systems 107:557-568. https://doi.org/10.1016/j.ijepes.2018.12.015

Wang L et al. (2021) Grid impact of electric vehicle fast charging stations: trends, standards, issues and mitigation measures - an overview. IEEE Open Journal of Power Electronics 2:56-74. 10.1109/OJPEL.2021.3054601

Xiang Y, Liu J, Tang S et al. (2016) A traffic flow-based planning strategy for optimal siting and sizing of charging stations. In: AsiaPacific Power and Energy Engineering Conf (APPEEC), Brisbane, Australia, pp 1-5. https://doi.org/10.1109/APPEEC.2015.7380895

Xiang Y, Hu S, Liu Y, Zhang X, Liu J (2019) Electric vehicles in smart grid: a survey on charging load modelling. IET Smart Grid 2(1):25-33. https://doi.org/10.1049/iet-stg.2018.0053

Yadav AS, Yadav VK, Mukherjee V, Ghosh S (2021) Performance Investigation of Different Bypass Diode Topology Based SDK-PV Arrays Under Partial Shading Conditions. In: Favorskaya M., Mekhilef S., Pandey R., Singh N. (eds) Innovations in Electrical and Electronic Engineering. Lecture Notes in Electrical Engineering, vol. 661, pp. 261-270. Springer, Singapore. https://doi.org/10.1007/978-981-15-4692-1_20.

Yang B, Wang L, Liao C, et al. (2015) Charging load calculation method of large-scale electric vehicles with coupling characteristics. Automation of Electric Power Systems 39(22):76-82 
Zhao J, Wen F, Yang A, et al. (2011) Impacts of electric vehicles on power systems as well as the associated dispatching and control problem. Automation of Electric Power Systems 35(14):2-10

Zhang H, Hu Z, Song Y, et al. (2014) A prediction method for electric vehicle charging load considering spatial and temporal distribution. Automation of Electric Power Systems 38(1):13-20

Zhang Y, Ho SL, Fu W (2018) Applying Response Surface Method to Oil-Immersed Transformer Cooling System for Design Optimization. IEEE Transactions on Magnetics 54(11):1-5. https://doi.org/10.1109/TMAG.2018.2840337

Zhang H, Tang L, Yang C, Lan S (2019) Locating electric vehicle charging stations with service capacity using the improved whale optimization algorithm. Advanced Engineering Informatics 41:1-14. https://doi.org/10.1016/j.aei.2019.02.006

Zhao Y et al. (2020) Deployment of the electric vehicle charging station considering existing competitors. IEEE Transactions on Smart Grid 11(5): 4236-4248. 10.1109/TSG.2020.2991232

Zeb M Z et al. (2020) Optimal placement of electric vehicle charging stations in the active distribution network. IEEE Access 8:6812434. 10.1109/ACCESS.2020.2984127

\section{Foot Notes:}

${ }^{1}$ For the present case, Tata Starbus Ultra Electric 9/12 EV, 41 seaters electric bus (manufactured by Tata Motors, India) having PMAC traction motor of $145 \mathrm{~kW}$ power, has been considered. The time taken to get fully charged by NCT is 7 hours, and by FCT is 2 hours, 15 minutes with UFCT and 5 minutes with BST.

${ }^{2}$ A subsidy of $70 \%$ earmarked by GoI on electrical vehicle supply equipment includes chargers, cable, smart metering, energy meter, breakers, etc. The upstream electrical infrastructure investment (which also includes transformers) is not included under this subsidy. As of now, there is no clarity on subsidy on spare batteries for the swapping process. 